\title{
DOWNWARD NOMINAL
} WAGE RIGIDITY IN THE OECD

by Steinar Holden and Fredrik Wulfsberg

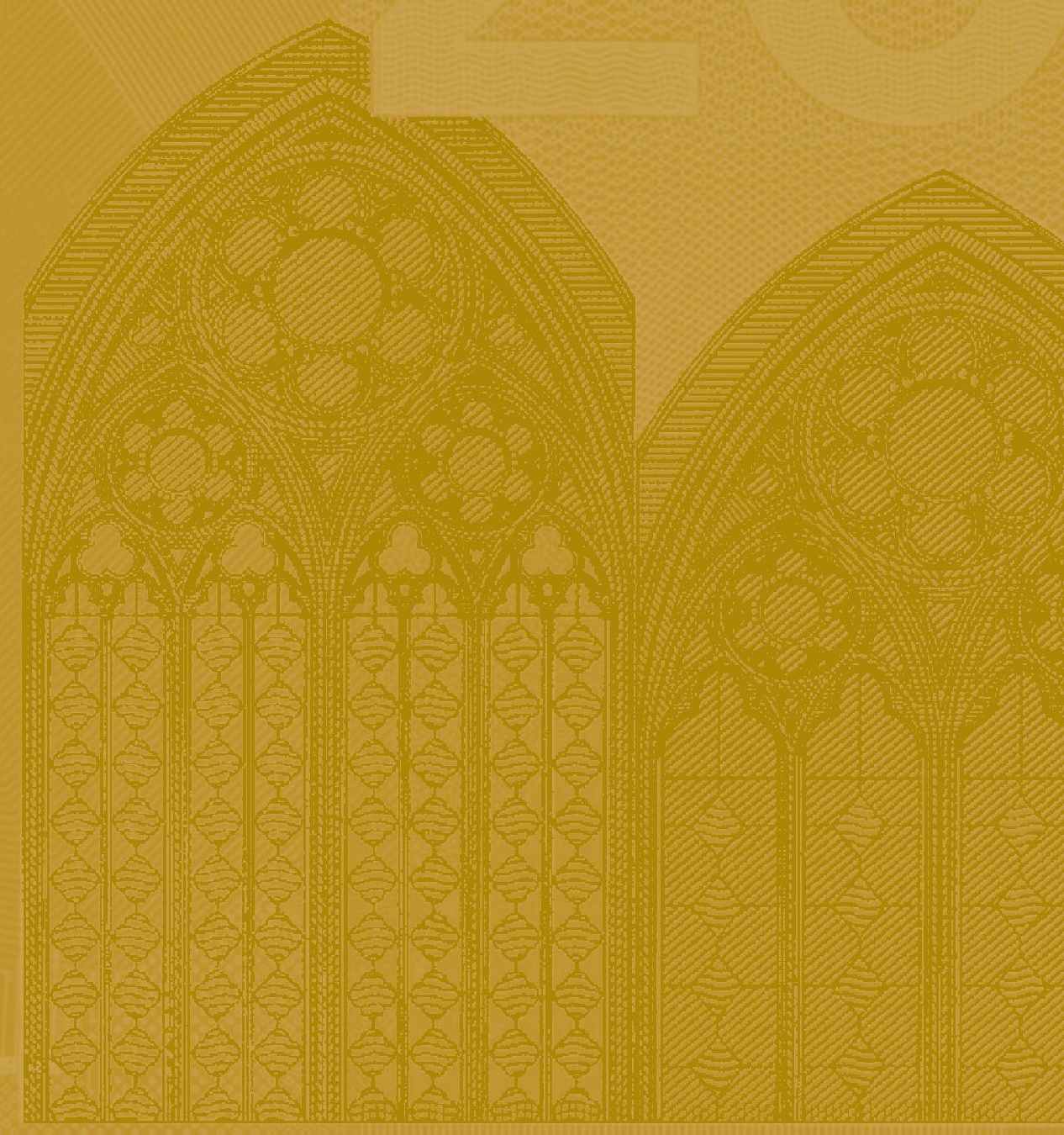


EUROSYSTEM

\title{
WORKING PAPER SERIES
}

NO 777 I JULY 2007

\author{
ECB/CEPR LABOUR \\ MARKET WORKSHOP ON \\ WAGE AND LABOUR \\ COST DYNAMICS

\section{DOWNWARD NOMINAL WAGE RIGIDITY IN THE OECD I}

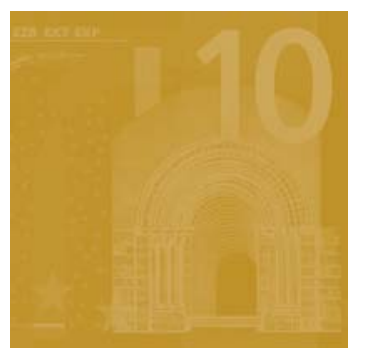

by Steinar Holden ${ }^{2}$

and Fredrik Wulfsberg ${ }^{3}$

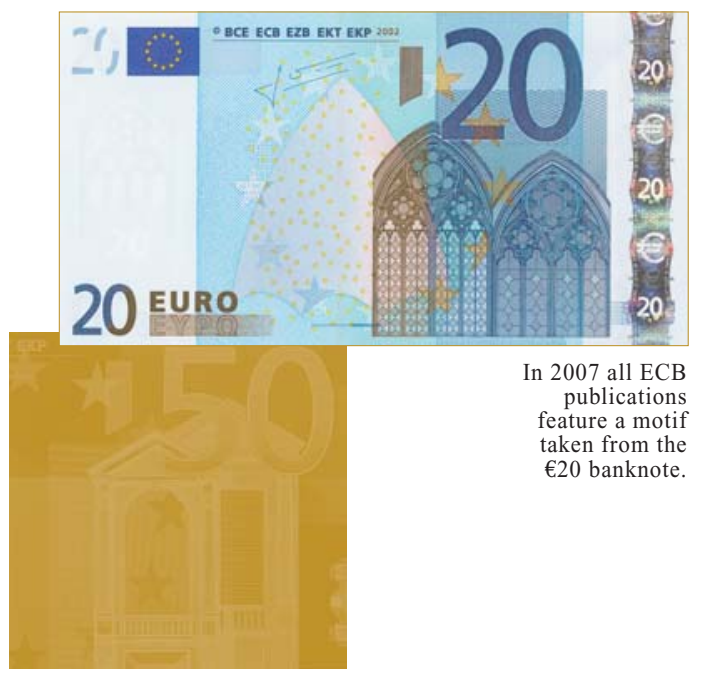

This paper can be downloaded without charge from http://www.ecb.int or from the Social Science Research Network electronic library at http://ssrn.com/abstract_id $=667224$.

\footnotetext{
I We wish to thank Lars Holden and Tore Schweder for invaluable help in the formulation of the statistical methods that we use. We are also grateful to Guiseppe Bertola, Bill Dickens, Mike Elsby, Nils Gottfries, Christoph Knoppik, Alan Manning, Halvor Mehlum, Harald Uhlig and seminar participants at ECB-CEPR, ESEM2003, Norges Bank, IZA Bonn, and at the universities of Oslo, Uppsala, Umeå and Copenhagen for useful comments to earlier drafts. Views and conclusions expressed in this paper are those of the authors alone and cannot be attributed to Norges Bank. 2 University of Oslo, Norges Bank and CESifo, Department of Economics, University of Oslo, Box 1095 Blindern, 0317 Oslo, Norway; e-mail:steinar.holden@econ.uio.no 3 Norges Bank and Federal Reserve Bank of Boston, Box II 79 Sentrum, 0107 Oslo, Norway; 


\section{ECB/CEPR Labour Market Workshop on "Wage and Labour Cost Dynamics"}

This paper was presented at the ECB/CEPR Labour Market Workshop on "Wage and Labour Cost Dynamics", held on 14-15 December 2006 in Frankfurt am Main, Germany. The workshop was organized by Torben M Andersen (Universitet Aarhus and CEPR), Samuel Bentolila (CEMFI and CEPR), Ana Lamo (ECB) and Jarkko Turunen (ECB). The conference programme, including papers, can be found on the ECB's web site http://www.ecb.int/events/conferences/html/wage_and_labour.en.html

The views expressed in the paper are the author's own and do not necessarily reflect those of the Eurosystem.

\footnotetext{
(C) European Central Bank, 2007

Address

Kaiserstrasse 29

60311 Frankfurt am Main, Germany

Postal address

Postfach 160319

60066 Frankfurt am Main, Germany

Telephone

+496913440

Internet

http://www.ecb.int

Fax

+496913446000

Telex

411144 ecb d

All rights reserved.

Any reproduction, publication and reprint in the form of a different publication, whether printed or produced electronically, in whole or in part, is permitted only with the explicit written authorisation of the ECB or the author(s).

The views expressed in this paper do not necessarily reflect those of the European Central Bank.

The statement of purpose for the ECB Working Paper Series is available from the ECB website, http://www.ecb.int. 


\section{CONTENTS}

Abstract 4

1 Non-technical summary 5

2 Introduction 8

3 DNWR and industry wages 9

4 Empirical approach ||

4.1 Constructing the notional distribution 13

4.2 Testing the significance of DNWR $\quad 16$

5 Results 17

5.1 Robustness 22

6 Explaining the number of wage cuts 25

7 Conclusions 29

References 3।

A Data appendix 34

B Results with country specific and period specific underlying distributions and country-year specific symmetric distribution

European Central Bank Working Paper Series 


\begin{abstract}
Recent micro studies have documented extensive downward nominal wage rigidity (DNWR) for job stayers in many OECD countries, but the effect on aggregate variables remains disputed. Using data for hourly nominal wages, we explore the existence of DNWR on wages at the industry level in 19 OECD countries, over the period 1973-1999. Based on a novel method, we reject the hypothesis of no DNwR. The fraction of wage cuts prevented due to DNWR has fallen over time, from 61 percent in the 1970s to 16 percent in the late 1990s, but the number of industries affected by DNwR has increased. DNWR is more prevalent when unemployment is low, union density is high, and employment protection legislation is strict.
\end{abstract}

JEL: E3, J3, J5

Keywords: Downward nominal wage rigidity, OECD, employment protection legislation, wage setting 


\section{Non-technical summary}

The optimal inflation target depends of the costs and benefits of inflation. One of the possible benefits of inflation that has attracted most attention is that it may grease the workings of the labour market. As argued by Tobin (1972), if wages are rigid downwards in nominal terms, the existence of some inflation will reduce the risk that downward wage rigidity is binding. Hence some inflation will alleviate wage pressure, thus involving a permanent reduction in unemployment.

However, the practical relevance of this effect is heavily disputed. The discussion is less on the existence of downward nominal wage rigidity (DNWR), as there is now a number of empirical studies on micro data that have found considerable DNWR for job stayers in most OECD countries, including the International Wage Flexibility Project (Dickens et al., 2006). The key issue of contention is whether this DNwR at individual level matters for monetary policy.

On the one hand, several studies find that DNWR and/or low inflation is associated with higher unemployment (see e.g. Fehr and Gotte (2005), Akerlof et al., 1996, Karanassou et al., 2003 and Dickens et al., 2006). On the other hand, many economists are skeptical towards the reliability of these findings (e.g. Gordon, 1996, Camba-Mendez et al., 2003, Mankiw, 1996 and Svensson, 2001). In ECB's recent evaluation of its monetary policy framework, it is concluded that '. . . the importance in practice of downward nominal rigidities is highly uncertain and the empirical evidence is not conclusive, particularly for the euro area' (ECB, 2003, page 14).

A possible reason for the contradictory aggregate evidence of DNWR, in spite of strong microeconomic evidence, may be that the DNWR at the individual level is undone by firm behaviour and market mechanisms. Indeed, studying the wage adjustments of different groups of Canadian employees, Fares and Lemieux (2000) conclude that the bulk of the real-wage adjustment over the business cycle is experienced by new entrants, for whom DNwR is least likely to bind. These results are consistent with the findings of Card and Hyslop (1997), who based on US data find evidence of DNWR for individual workers, but no corresponding evidence on state-level data.

To explore the potential existence of DNWR in wages at more aggregate levels, we study industry level wage data for 19 OECD countries, for the period 1973-99. Following previous studies, we test for DNWR by comparing the empirical wage change distributions with a postulated notional or counterfactual wage change distribution (i.e. the assumed distribution under flexible wages). The notional wage change distributions are constructed on the basis of observations from country-years when the wage growth is high, i.e. when DNWR is not likely to bind. A novelty of our approach is that we construct country-year specific notional probabilities of 
wage cuts from the notional country-year specific distributions. Given these notional probabilities, we can compute the probability distribution for the notional number of wage cuts, and compare the empirical number of wage cuts with this distribution. Thus, we can calculate the exact p-value for the empirical number of wage cuts, under the Null hypothesis of no DNwR.

We find that one out of four of the wage cuts that should have taken place under complete flexibility (notional wage cuts), have been prevented by DNWR, while slightly more than one percent of all industry-year observations have been affected by binding DNWR. These results are robust to a number of different modifications of the key assumptions.

Our paper makes three main contributions to the literature on DNWR. First, by documenting the existence of DNWR at industry level data, we show that firm behaviour and market mechanisms may diminish, but do not remove, rigidity at individual level. In this sense we view our study as complementary to the increasing number of studies that document the existence of DNWR in micro data.

Second, we explore whether the extent of DNWR can be explained by economic and institutional variables. We find that stricter employment protection legislation (EPL) and higher union density lead to stronger DNWR: In country-year samples with strict EPL and high union density, the incidence of nominal wage cuts is reduced significantly. The estimated effects of the institutional variables that we find are fairly strong. For example, weakening the EPL from a strict to a medium level would, according to the point estimates, raise the incidence of nominal wage cuts in Portugal from 0.7 to 2.3 percent. Thus, our results suggest that changing labour market institutions would have a considerable impact on wage rigidities.

The effect of institutional variables is consistent with differences in DNWR across countries. Splitting countries into groups, we find stronger DNwR in two groups, the South (Italy, Greece, Portugal, Spain) and the Nordic region (Denmark, Finland, Norway and Sweden), where EPL is stricter and/or unions are stronger than in the other groups; the Core (Austria, Belgium, France, Germany, Luxembourg, Netherlands), and the Anglo region (Canada, Ireland, New Zealand, the UK and the Us).

These findings support that idea that DNWR is in part being caused by contracts and institutional features, as argued by MacLeod and Malcomson (1993) in a individual bargaining framework, and Holden (1994) in a collective agreement framework. Interestingly, the micro study of Dickens et al. (2006) does not find the same positive effect of EPL and union density on DNWR that we do. One possible explanation for this difference is that DNWR for individual workers can be undone by wage flexibility for other workers or in other firms, unless prevented by strict EPL and/or union contracts. For example, for a firm facing a union contract, it would be difficult to circumvent wage rigidities by replacing high-wage workers by low-wage workers. However, as we have not be able to test for fairness and morale explanations of DNwR, such hypotheses remain speculative. 
The third contribution is that we explore the change in DNWR over time. We find that DNWR in the form of the fraction of notional wage cuts that is prevented by DNWR has fallen over time, from 60 percent in the 1970s to 16 percent in the late 1990s. The fall in inflation has nevertheless implied that more industries are affected by DNWR. We find that the fraction of industry-years affected by DNWR has increased from 0.4 percent in the 1970s to 1.7 percent in the late 1990s.

Overall, our finding of DNWR yields clear additional support to the idea that DNWR has some, but moderate impact on firms' wage costs in many OECD countries, especially in Europe. 


\section{Introduction}

Recent micro economic studies have found considerable downward nominal wage rigidity (DNWR) for job stayers in OECD countries. The International Wage Flexibility Project (Dickens et al., 2006) finds that for all the 16 countries that are studied, DNWR prevents wage cuts from taking place, with the fraction of wage cuts prevented being in the range of 9-66 percent, see literature review in section 3 below. The extensive DNWR found in micro studies, combined with monetary policy aiming for low rates of inflation, make Tobin's contention that this combination leads to greater wage pressure and higher unemployment (Tobin, 1972) again of great policy relevance.

However, when it comes to identifying the aggregate effects of DNWR, the results are more disputed. Fehr and Gotte (2005) show that DNWR is associated with higher unemployment among Swiss cantons. Moreover, several papers have found empirical support for Tobin's contention (see e.g. Akerlof et al., 1996, Karanassou et al., 2003 and Dickens et al., 2006), yet other economists are skeptical towards the reliability of these findings (e.g. Gordon, 1996, Camba-Mendez et al., 2003, Mankiw, 1996 and Svensson, 2001). In ECB's recent evaluation of its monetary policy framework, it is concluded that '... the importance in practice of downward nominal rigidities is highly uncertain and the empirical evidence is not conclusive, particularly for the euro area' (ECB, 2003, page 14).

One possible explanation for the disputable aggregate evidence of DNWR, in spite of strong microeconomic evidence, may be that the DNWR at the individual level is undone by firm behaviour and market mechanisms. Fares and Lemieux (2000) point out that DNwR for 'stable' workers may not prevent employers from hiring new workers at lower nominal wages than they would have done in other circumstances. Indeed, studying the wage adjustments of different groups of Canadian employees, Fares and Lemieux conclude that the bulk of the real-wage adjustment over the business cycle is experienced by new entrants, for whom DNwR is least likely to bind. Furthermore, they argue that this may explain why DNwR has little effect on aggregate wage setting, despite it being important for some groups of workers. Fares and Lemieux' results are consistent with the findings of Card and Hyslop (1997), who on Us data find evidence of DNWR for individual workers, but no corresponding evidence on state data.

To explore the effect of DNwR on wages at more aggregate levels, we study industry level wage data for 19 OECD countries, for the period 1973-99. Based on the idea of previous studies, we construct the notional wage change distribution (i.e. the assumed distribution under flexible wages) on the basis of observations from country-years when the wage growth is high and thus DNWR is not likely to bind. However, our method for comparing the notional and empirical wage change distributions is simple and novel. Based on the notional wage change distributions, 
we construct country-year specific notional probabilities of a wage cut. Given these notional probabilities, we can compute the probability distribution for the number of notional wage cuts, and compare with the number of empirical wage cuts. Thus, we can calculate the exact p-value for the number of empirical wage cuts, under the Null hypothesis of no DNwR, as given by the notional probabilities. In section 5, we document the empirical results and discuss the robustness of our method. Our robustness tests indicate that the method is able to detect more than 90 percent of the DNWR that exists in the data.

In addition to investigating the extent of DNWR in aggregate data, we explore in Section 6 potential determinants of DNWR that are suggested in the theoretical literature. As we have a panel of 19 countries over 27 years, we are able to explore the effect on DNWR of economic and institutional variables like inflation, unemployment, employment protection legislation, and union density, which are often difficult to evaluate in studies from a single country. We find that DNWR is more prevalent under high union density and strict employment protection legislation. Such information is useful as it sheds light on both possible explanations for DNWR, and on how the extent of DNWR might be affected by economic policy. Section 7 concludes the paper.

\section{$3 \quad$ DNWR and industry wages}

Empirical work on DNWR have grown rapidly in recent years, with various types of evidence. Blinder and Choi (1990), Akerlof et al. (1996), Bewley (1999) and Agell and Lundborg (2003), among others, report evidence of DNWR based on interviews and surveys of employees and employers. However, the great majority of studies explores large micro-data sets, based on personnel files, survey data or administrative data, and following either of two types of approaches. The first type, initiated by the skewness-location approach of McLaughlin (1994), focuses on the effect of inflation on the distribution of wage changes; Kahn (1997), Christofides and Leung (2003), Lebow et al. (2003), Nickell and Quintini (2003) and Elsby (2006) are some of the recent applications. The second type, referred to as the earnings function approach by Knoppik and Beissinger (2003), adds other explanatory variables that are usually included in wage equations, see e.g. Fehr and Gotte (2005) and Altonji and Devereux (2000). More recently, multi-country studies by Dessy (2002), Knoppik and Beissinger (2005) and Dickens et al. (2006) have strengthened the evidence of extensive DNWR in most or all OECD countries.

The clear evidence of DNWR for individual workers is not reflected in a similar consensus on the macro economic effects of DNWR. While a few papers find evidence of DNWR on aggregate time-series data, see e.g. Holden (1998), Fortin and Dumont (2000) and Wyplosz (2001), these effects are disputed. This motivates a closer look at the link from individual DNwR to aggregate effects. We focus on one part of this link, whether DNWR is apparent in wages at industry level. 
Micro studies typically explore the change in hourly earnings of job stayers, while the observational unit in our data is the change in the average hourly earnings for all manual workers in the industry. Numerically, the difference between these data types can be grouped in two. First, our data entails averaging over all job stayers, second, our data are affected by compositional changes, i.e. that the wages of new workers differ from the wages of those who leave. Concerning the first component, averaging over job stayers may mask wage cuts for single workers if other workers receive wage increases. This will tend to reduce the incidence of nominal wage cuts (given that the economy-wide wage change is positive), as the average wage change has a lower variance than individual wage changes.

As for compositional changes, one may expect to find both systematic and random effects. First, there will be a systematic negative effect on wage growth, as older workers who leave the labour force on average have higher wages than younger, newcomers to the labour market. Second, one may expect systematic cyclical effects, as the share of low-skilled workers may decrease in recessions, cf. Solon et al. (1994) and Fares and Lemieux (2000). The lower share of low-skilled workers in recessions will ceteris paribus lead to higher average wages, thus it will reduce the number of wage cuts in recessions, when they are most likely. A third point is that the compositional effects will depend on to what extent job movements in general are part of a career upwards, involving higher wages, or whether job movements instead might be undertaken by less productive workers leaving for jobs with lower job requirements. As the former two effects have opposite impact on the number of wage cuts, and the third is ambiguous, the overall effect is clearly ambiguous. Turnover also involves a random element which may be considered as 'noise' relative to individual wage rigidity. The noise effect will imply that we find more wage cuts, and thus less rigidity.

Another issue that needs consideration, is to what extent binding DNWR for some workers may affect the wages of other workers in the industry. One such effect would be if firms respond to downward rigidity for some workers by e.g. giving lower wage increases to other workers, or by changing the composition of the workforce, as suggested by Fares and Lemieux (2000). Workers who have their wage cut may also quit voluntarily, and new workers could take their job at the lower pay.

Binding DNWR in one firm might also affect wages in other firms. For example, in recessions with negative productivity or demand shocks, firms that cannot lower their wages due to DNWR may respond by laying off workers, or at least reduce the hiring of new workers. If workers have industry-specific skills, the higher number of unemployed workers might contribute to lower wages in other firms in the industry, where wages are flexible, thus offsetting the effect of DNWR in the inflexible firms. However, the extent to which this will happen depends on how wages are set in the remaining firms. If wage setting in other firms are influenced by e.g. unions 

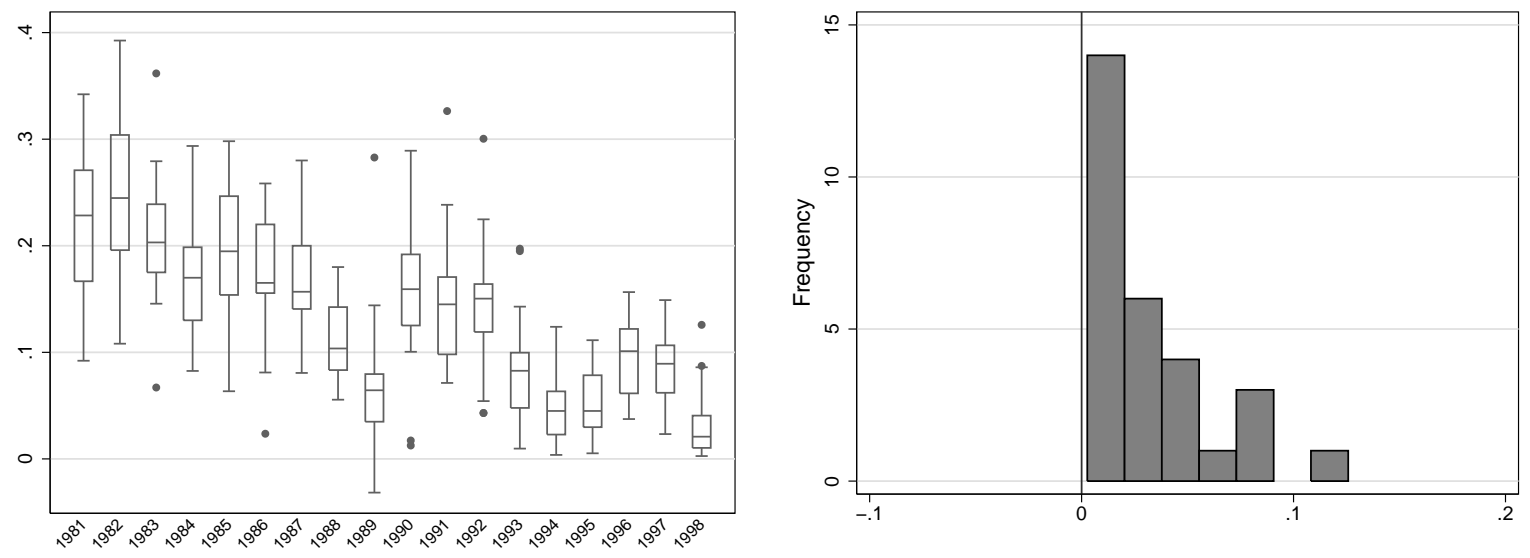

Figure 1: Box plots of annual wage growth in Portugal (left) and histogram of annual wage growth in 1998 (right). The box plot illustrates the distribution of wage changes within a country-year. The box extends from the 25th to the 75th percentile with the median inside the box. The whiskers emerging from the box indicate the tails of the distributions and the dots represent outliers.

or employment protection legislation, the workers in these firms may resist the dampening effect on wages of higher unemployment. In this case the industry effect of DNWR in some firms is not undone.

\section{Empirical approach}

We use an unbalanced panel of industry level data for the annual percentage growth of gross hourly earnings for manual workers from the manufacturing, mining and quarrying, electricity, gas and water supply, and construction sectors of 19 OECD countries in the period 1973-1999. The countries included in the sample are Austria, Belgium, Canada, Germany, Denmark, Spain, Finland, France, Greece, Ireland, Italy, Luxembourg, Netherlands, Norway, New Zealand, Portugal, Sweden, the UK and the Us. The main data source for wages are harmonised hourly earnings from Eurostat and wages in manufacturing from ILO. ${ }^{1}$ One observation is thus denoted $\Delta w_{j i t}$ where $j$ is index for industry, $i$ is index for country and $t$ is index for year. There are all together 9509 wage change observations distributed across 449 country-year samples, on average 21 industries per country-year. Figure 1 illustrates the data for Portugal over time (left) and for Portugal in 1998 (right). We see that the median wage growth and dispersion fall over time and that there were many small observations of wage increases in 1998. There are no nominal wage cuts in $331(74 \%)$ of the country-year samples. We observe, however, no less than $Y=324$ events of nominal wage cuts, i.e. an incidence rate of $q=3.4$ percent of all observations. Table A1 in the data appendix for the detailed distribution of wage cuts and observations across countries and years. The data appendix provides more details on the data.

\footnotetext{
${ }^{1}$ The data for Austria, Canada, Finland, New Zealand, Sweden and the Us are from the ILO, while the data for Norway is from Statistics Norway. The data from the other countries are from Eurostat.
} 
To detect DNWR we use a novel variant of the skewness-location approach of McLaughlin (1994), where the empirical distribution of wage changes is compared to a postulated notional distribution, i.e. a counterfactual wage change distribution assumed to prevail in the absence of DNWR. The key issue in this approach is clearly how to derive the notional distribution. In the literature, two main approaches have been used, either to assume that the notional wage change distribution is symmetric (e.g. Lebow et al. (1995), Card and Hyslop (1997) and Dickens et al. (2006)), or to assume that the shape of the notional wage change distributions is common across time, (e.g. Kahn, 1997 and Nickell and Quintini, 2003). In the latter case the shape of the notional distribution is derived from years with high inflation, where presumably DNWR does not affect the wage change observations. Elsby (2006) shows that if wages are rigid downwards, firms will respond by compressing wage increases. This would cause the symmetry method to involve a downward bias in the estimated DNWR. In addition, the wage change distribution may be asymmetric for other reasons than DNWR, for example if industries are subject to different shocks. Thus, our main method is based on a common shape assumption. However, for robustness we will also compare with the results using a symmetry assumption.

One popular test of the common shape type, suggested by (Kahn, 1997), explores the effect of inflation on the height of histogram bars of the wage change distribution. However, the Kahn test relies on the assumption that the notional wage change distribution is invariant to inflation. This property is violated in our case, as both the median wage growth and the dispersion fall over time in our data, and both have a strong positive correlation with inflation (correlation coefficients are 0.87 and 0.42 respectively). This is illustrated for Portugal in Figure 1. The Nickell and Quintini (2003) method is based on the assumption (or approximation) that the probability of a nominal wage cut is a function of the median and the dispersion of the wage changes, with a quadratic term in the former. This approximation is exact if the density function of wage changes is linear over the appropriate range. As we shall see below (Figure 2 ), the density function in our data is highly non-linear in the range that is relevant for DNWR. Thus, this method also involves problematic assumptions in our case.

A further issue is that in most micro studies of DNWR, there has been a focus on the existence of a spike at zero wage growth, caused by DNwR. Due to compositional effects and averaging over many workers, there is no spike at zero in our data. Thus, as will be clear below, we instead focus on the extent of missing wage cuts in the empirical distributions.

We construct the notional wage change distributions on the basis of country-year samples with high median nominal and real wage growth, to minimize the effect of possible downward nominal and real wage rigidity. However, to allow for the large variation that exists across countries and time with respect to monetary policy, wage setting and industry structure, we 
include country-year specific variation in the location (median) and dispersion of the notional wage change distributions. Thus, we only impose the same shape in all country-years, but not the same location and dispersion. This corresponds to assuming the same two-parameter distribution for all country-years, except that we have not chosen a specific parametric distribution, but use the shape of the empirical wage change distribution from the high inflation years. Note that an alternative assumption, common in regression based studies, namely that the notional distribution is normal, would not be suitable due to the higher peak and fatter tails of the empirical distribution, see Figure 2. By allowing for country-year specific variation in the median and the dispersion, in line with Nickell and Quintini (2003), our approach is less restrictive than other approaches often used in the literature. Furthermore, in section 5.1 below, we report results from a number of alternative assumptions including symmetry, as a check of the robustness of our results.

\subsection{Constructing the notional distribution}

More specifically, the notional distributions are constructed as follows. First, we construct the underlying distribution based on a subset $H$ of the sample, with $S^{H}=1331$ observations from the 66 country-year samples where both the median nominal and the median real wage growth are among their respective upper quartiles. ${ }^{2}$ To avoid as far as possible that the measures of location and dispersion are affected by DNWR and outliers, we follow Nickell and Quintini (2003) and measure the location by the median, and the dispersion by the range between the 75th and the 35th percentiles, rather than the mean and the standard deviation (we have also tried other measures with similar results). The underlying distribution of wage changes is then constructed by use of the 66 samples with high median nominal and real wage growth, by subtracting the corresponding country-year specific median $\left(\mu_{i t}\right)$ and dividing by the inter percentile range $\left(P 75_{i t}-P 35_{i t}\right)$, i.e.

$$
\Delta w_{s}^{u} \equiv\left(\frac{\Delta w_{j i t}-\mu_{i t}}{P 75_{i t}-P 35_{i t}}\right), \quad \forall j, i, t \in H \text { and } s=1, \ldots, S^{H}
$$

where subscript $s$ runs over all $j, i$ and $t$ in the 66 country-year samples. Figure 2 compares the underlying distribution of wage changes (illustrated by the histogram and the kernel density in solid line) with the standard normal distribution (dotted line); we notice that the underlying distribution is asymmetric as it slightly skewed right. ${ }^{3}$

Then, for each of the 449 country-years in the overall sample, we construct a notional

\footnotetext{
${ }^{2}$ Thus, in these country-year samples, the median nominal wage growth is above the 3rd quartile of 11.8 percent, and the median real wage growth is above 2.8 percent. Four of 1331 observations are below five percent nominal wage growth, of which only one is negative.

${ }^{3}$ The coefficient of skewness is 0.26 .
} 


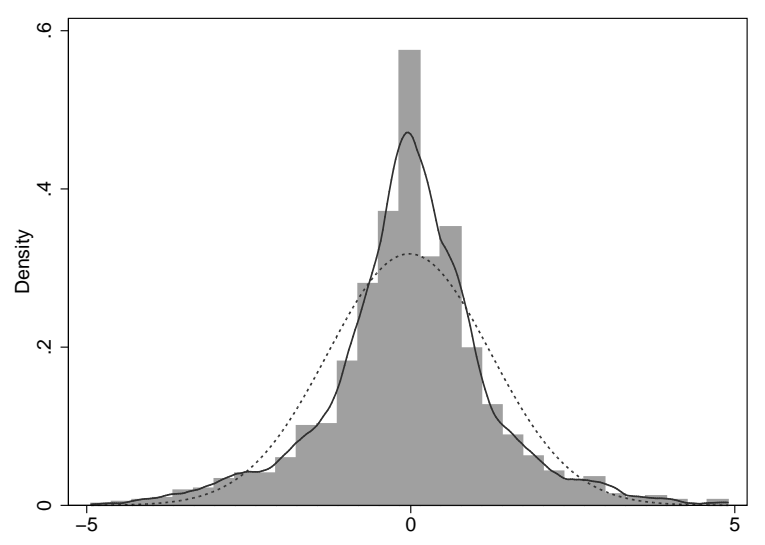

Figure 2: Histogram and kernel density (solid line) of the normalised underlying distribution of wage changes compared to the normal density (dotted line). 14 extreme observations are omitted.

country-year specific distribution of wage changes by adjusting the underlying wage change distribution for the country-specific observed median and inter percentile range

$$
\Delta \widetilde{w}_{s}^{i t} \equiv \Delta w_{s}^{u}\left(P 75_{i t}-P 35_{i t}\right)+\mu_{i t}, \quad \forall i, t, \text { and } s=1, \ldots, S^{H}
$$

Thus, we have then constructed 449 notional country-year samples, each consisting of $S^{H}=$ 1331 wage change observations. These notional country-year samples have by construction the same median and interpercentile range as their empirical country-year counterparts, whereas the shape is common for all notional country-year samples, given by the shape of the underlying distribution.

Given the notional country-year specific distributions, we can explore the extent of DNWR by comparing the notional and the empirical distributions. The point estimate of the extent of DNWR follows directly from comparing the incidence of wage cuts in the empirical and the notional distributions. Thus, for all country-year samples it we calculate the empirical incidence rate as

$$
q_{i t}=\frac{\# \Delta w_{j i t}<0}{S_{i t}}, \quad \forall j
$$

where $\# \Delta w_{j i t}<0$ is the number of wage cuts and $S_{i t}$ is the number of observations in countryyear $i t$. The notional incidence rate is calculated as

$$
\tilde{q}_{i t}=\frac{\# \Delta \widetilde{w}_{s}^{i t}<0}{S^{H}}, \quad s=1, \ldots, 1331
$$

For country-years where there is at least one notional wage cut, implying that $\tilde{q}_{i t}>0$, we can calculate an often used measure of DNWR, which is the fraction of wage cuts prevented, FWCP 

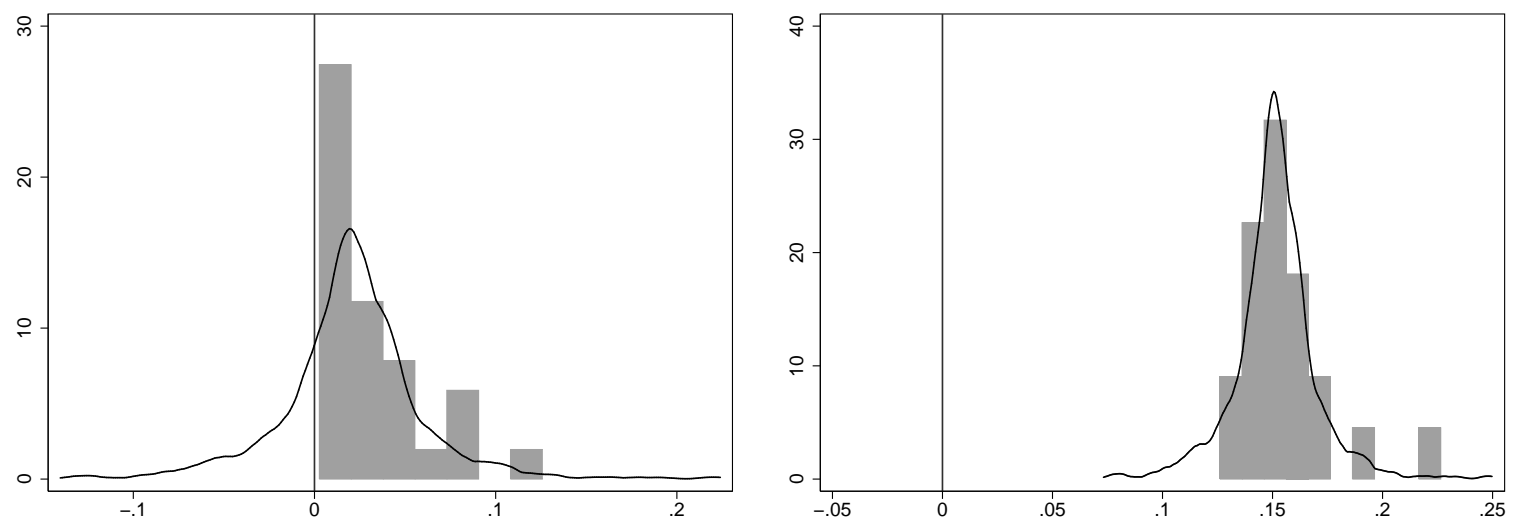

Figure 3: Left: Histogram of observed wage changes and the notional wage change distribution (solid line) in Portugal 1998. Right: Histogram of observed wage changes and the notional wage change distribution (solid line) in France 1981.

defined as

$$
F W C P_{i t}=1-q_{i t} / \tilde{q}_{i t}
$$

If, for example, the incidence of wage cuts in the empirical sample is half of that in the notional distribution, then $F W C P=0.5$. Note that if the empirical incidence rate is larger than the notional, the FWCP is negative. Figure 3 illustrate these measures for Portugal 1998 and France 1981. By construction, the empirical distribution (histogram) and the notional distribution (for illustrative purposes, we use the kernel density) for the same country-year have the same median and inter percentile range, but the shapes differ. In Portugal 1998 the incidence rate of notional wage cuts is 0.22 , while the empirical incidence rate is zero, clearly suggesting the existence of DNWR with a FWCP of unity. The empirical and notional incidence rates are zero for France 1981, so the FWCP is not defined. Obviously there is a lot of variation in the incidence rates (and thus the FWCP) across the country-year samples, which are reported in Table A2 in the appendix. ${ }^{4}$ In order to look for interesting patterns in these estimates across countries, we will calculate aggregate incidence rates and the FWCP for countries, periods as well as the overall sample (i.e. all country-years).

We aggregate the country-year estimates by pooling the empirical observations in the relevant sample (eg all country-years) implying that the country-year notional incidence rates are weighted according to the number of observations within the country-year. For the overall sample, the fraction of wage cuts prevented is $F W C P=1-q / \tilde{q}=1-0.034 / 0.046=0.259$. Thus, about one out of four notional wage cuts in the overall sample does not result in an observed wage cut due to DNWR. A probably better measure of the economic relevance of DNWR is the probability than an observation is affected by DNWR. An estimate of this probability

\footnotetext{
${ }^{4}$ The empirical and notional incidence rates are zero for 140 country-year samples, while a FWCP of unity is observed in 196 country-years.
} 
is the fraction of industry-years affected calculated by the difference between the notional and empirical incidence rates, i.e. $(\tilde{q}-q)$. For the overall sample this fraction is 0.012 i.e. about one out of 100 observations (industry-years) were affected by DNwR.

Below we will present estimates of the fraction of wage cuts prevented by DNWR and fraction of industry-years affected for different countries, regions and periods. But before that we provide a statistical test of the significance of our estimates.

\subsection{Testing the significance of DNWR}

To test whether our estimates of the FWCP are statistically significant, we exploit that the incidence rate in the notional wage change distribution can be viewed as the probability of a wage cut if there was no DNwR. In other words, under the Null hypothesis of no DNwR, the number of wage cuts in country-year it with, say, 20 industries, is given by 20 independent draws from the binomial distribution with probability $\tilde{q}_{i t}$. Using the formulae for binomial distributions, we can then calculate the exact probability for any number of wage cuts for each country-year under the Null hypothesis of no rigidity, see Table A2. The estimate of FWCP is significantly larger than 0 at the $10 \%$ level for ten country-years only, which is not very surprising given the few number of observations per country-year samples. ${ }^{5}$

For samples covering more than one country-year, the number of wage cuts under the Null hypothesis of no DNWR, is given by the combination of several binomial distributions, with respective incidence rates $\tilde{q}_{i t}$ as probabilities. Thus, in principle, we can also compute the exact probability of significance (p-value) for the number of wage cuts in the empirical distribution for these samples. This calculation is, however, computationally extremely demanding not only for the overall sample with 9509 observations, drawn from 449 different binomial distributions, but also for separate countries. ${ }^{6}$ Thus, we compute the p-values on the basis of simulations instead, which is computationally much simpler, and still highly accurate.

Specifically, our simulation method goes as follows. For each country-year it, we draw $S_{i t}$ times (i.e. the number of industries in country-year $i t$ ) from a binomial distribution with probability $\tilde{q}_{i t}$. We then add up all the simulated wage cuts for the aggregation level of interest, e.g. all country years $(\widehat{Y})$, and compare with the total number of wage cuts in the corresponding empirical distribution, $Y=324$. We then repeat this procedure 5000 times, and count the number of times where we simulate more notional wage cuts than we observe, for the overall sample denoted $\#(\widehat{Y}>Y)$. The Null hypothesis is rejected with a level of significance at

\footnotetext{
${ }^{5}$ These are Belgium $1987(F W C P=1, p=0.039)$, Canada 1987 (0.75, 0.076), Canada 1996 (0,77 0.045), Ireland 1992 (1, 0.094), Luxembourg 1993 (1, 0.091), New Zealand 1984 (0.73, 0.099), New Zealand 1991 (0.79, 0.039), Portugal 1995 (1, 0.031), Portugal 1998 (1, 0.008) and UK 1982 (1, 0.084).

${ }^{6}$ The number of terms in the formulae for the probability of $k$ wage cuts in a sample of $S$ observations is $S ! /(k !(S-k) !)$, which increases rapidly with the number of wage cuts. With $S=9509$ and $k=324$ in the overall sample the number of terms is $\exp (1409.5)$
} 
5 percent if $1-\#(\widehat{Y}>Y) / 5000 \leq 0.05$. We can also use the simulation results to obtain confidence intervals for our estimate of DNWR.

Note that if DNWR is at work in some country-year samples that are used in constructing the underlying wage change distribution, the underlying and notional wage change distributions will be compressed. Likewise, if DNWR compresses the inter percentile range in certain country year samples, the associated notional country year specific distribution will also be compressed. Thus, in these cases the notional probabilities will be biased downwards, reducing the number of simulated wage cuts. This will reduce the power of our test; an issue we shall return to below. However, under the Null hypothesis of no DNwR, there is no downward bias. Hence this aspect will not affect the significance level of our test.

\section{Results}

For the whole sample, there are more simulated than observed wage cuts in all 5000 simulations. Thus we reject the Null hypothesis of no DNWR comfortably with a p-value of 0 , as reported in the bottom line of the first column of Table 1. A number of interesting questions arise. Is there evidence for DNWR for different time periods, regions and countries? To what extent is DNWR related to labour market institutions?

We first investigate whether DNWR has changed over time by splitting the sample into four subperiods 1973-1979, 1980-1989, 1990-1994 and 1995-1999. From Table 1 we see that the number (and incidence) of wage cuts has increased over time as the average wage growth (and inflation) decreased while unemployment increased. DNWR is statistically significant in all periods. In the high-inflation 1970s, the fraction of wage cuts prevented was 61 percent. In the 1980s, it had fallen to 40 percent, and then further to 23 percent in the early 1990s and 16 percent in the late 1990s. However, the number of industry-years affected by DNwR increased from 0.4 percent in the 1970s to 1.7 percent in the late 1990s.

To investigate whether the change in DNWR over time is significant, we undertake Poisson regressions with the number of observed wage cuts in each country-year sample, $Y_{i t}$, as the dependent variable, and normalise on the average number of simulated wage cuts for country-

year sample, $\widehat{Y}_{i t}$. A Poisson regression seems appropriate as the endogenous variable is based on count data, see Cameron and Trivedi (1998). Adding a time trend, we obtain a trend coefficient of 0.036 , which is significant at the one percent level. Thus, the ratio of observed to simulated wage cuts has increased over time, implying that we can conclude that DNWR as measured by the fraction of wage cuts prevented, has fallen over time.

We then split the sample into four regions; Anglo (Canada, Ireland, New Zealand, the UK and the Us), Core (Austria, Belgium, France, Germany, Luxembourg and the Netherlands), 
Table 1: Results from 5000 simulations on subperiods.

\begin{tabular}{lccccc}
\hline Sample properties: & All observations & $1973-79$ & $1980-89$ & $1990-94$ & $1995-99$ \\
\hline No. of observations $(S)$ & 9509 & 2224 & 3717 & 1906 & 1662 \\
No. of country-years & 449 & 109 & 175 & 88 & 77 \\
Average wage growth & & $13.78 \%$ & $8.72 \%$ & $5.60 \%$ & $3.99 \%$ \\
Average inflation rate & & $10.30 \%$ & $8.13 \%$ & $4.42 \%$ & $2.19 \%$ \\
Average unemployment rate & & $3.71 \%$ & $6.72 \%$ & $8.49 \%$ & $8.07 \%$ \\
Observed wage cuts $(Y)$ & 324 & 5 & 74 & 93 & 152 \\
Incidence of wage cuts $(q)$ & 0.0341 & 0.0023 & 0.0199 & 0.0488 & 0.0915 \\
\hline Simulation results: & & & & & \\
\hline Fraction of wage cuts prevented $(F W C P)$ & 0.259 & 0.610 & 0.398 & 0.231 & 0.159 \\
Fraction of industry-years affected $(\hat{q}-q)$ & 0.012 & 0.004 & 0.013 & 0.015 & 0.017 \\
Probability of significance $(p)$ & 0 & 0.013 & 0.000 & 0.002 & 0.006 \\
\hline
\end{tabular}

Note: $p=1-\#(\widehat{Y}>Y)$ where $\#(\widehat{Y}>Y)$ is the number of simulations where we simulate more wage cuts $(\widehat{Y})$ than we observe $(Y) . q$ and $\hat{q}$ are the empirical and average simulated incidence rates respectively.

Table 2: Results from 5000 simulations on regions.

\begin{tabular}{lcccc}
\hline Sample properties: & Anglo & Core & Nordic & South \\
\hline No. of observations $(S)$ & 2961 & 3110 & 1976 & 1462 \\
No. of country-years & 129 & 158 & 95 & 67 \\
Observed wage cuts $(Y)$ & 153 & 125 & 18 & 28 \\
Incidence of wage cuts $(q)$ & 0.0517 & 0.0402 & 0.0091 & 0.0192 \\
\hline Simulation results: & & & & 0.414 \\
\hline Fraction of wage cuts prevented $(F W C P)$ & 0.198 & 0.234 & 0.497 & 0.014 \\
Fraction of industry-years affected $(\hat{q}-q)$ & 0.013 & 0.012 & 0.009 & 0.002 \\
Probability of significance $(p) 0$ & 0.001 & 0.000 & 0.000 & \\
\hline
\end{tabular}

Note: See Table 1

Nordic (Denmark, Finland, Norway and Sweden) and South (Italy, Greece, Portugal and Spain), and report the results in columns $2-5$ in Table 2 . Note that the regions include countries with rather similar labour market institutions, cf. discussion below.

We find significant DNWR at the one percent level for all regions. The fraction of wage cuts prevented is high in two regions, 50 percent in the Nordic countries and 41 percent in the South. In the Anglo and Core groups, the FWCP is considerably lower, around 20 percent. This difference is roughly in line with what one would expect in view of the differences in labour market institutions (in the appendix, we report country-specific indices for labour market institutions). Based on a theoretical framework allowing for bargaining over collective agreements as well as individual bargaining, Holden (2004) argues that workers who have their wage set via unions or collective agreements have stronger protection against a nominal wage cut, thus the extent of DNWR is likely to be increasing in the coverage of collective agreements and in union density. For non-union workers, the strictness of the employment protection legislation (EPL) is key to 
Table 3: Results from 5000 simulations on regions and sub-periods.

\begin{tabular}{|c|c|c|c|c|c|}
\hline Region & & $1973-1979$ & 1980-1989 & 1990-1994 & $1995-1999$ \\
\hline \multirow{7}{*}{ Anglo } & No. of observations & 698 & 1149 & 595 & 519 \\
\hline & No. of country-years & 31 & 50 & 25 & 23 \\
\hline & Observed wage cuts & 0 & 26 & 59 & 68 \\
\hline & Incidence of wage cuts & 0 & 0.0226 & 0.0992 & 0.1310 \\
\hline & Fraction of wage cuts prevented & 1 & 0.452 & 0.185 & 0.018 \\
\hline & Fraction of industry-years affected & 0.002 & 0.019 & 0.023 & 0.002 \\
\hline & Probability of significance & 0.191 & 0.000 & 0.039 & 0.459 \\
\hline \multirow{7}{*}{ Core } & No. of observations & 794 & 1183 & 587 & 546 \\
\hline & No. of country-years & 41 & 60 & 30 & 27 \\
\hline & Observed wage cuts & 4 & 40 & 18 & 63 \\
\hline & Incidence of wage cuts & 0.0050 & 0.0338 & 0.0307 & 0.1154 \\
\hline & Fraction of wage cuts prevented & 0.515 & 0.304 & 0.243 & 0.144 \\
\hline & Fraction of industry-years affected & 0.005 & 0.015 & 0.010 & 0.019 \\
\hline & Probability of significance & 0.085 & 0.005 & 0.113 & 0.062 \\
\hline \multirow{7}{*}{ Nordic } & No. of observations & 474 & 888 & 354 & 260 \\
\hline & No. of country-years & 23 & 40 & 18 & 14 \\
\hline & Observed wage cuts & 1 & 3 & 12 & 2 \\
\hline & Incidence of wage cuts & 0.0021 & 0.0034 & 0.0339 & 0.0077 \\
\hline & Fraction of wage cuts prevented & 0.374 & 0.665 & 0.292 & 0.760 \\
\hline & Fraction of industry-years affected & 0.001 & 0.007 & 0.014 & 0.024 \\
\hline & Probability of significance & 0.520 & 0.016 & 0.107 & 0.009 \\
\hline \multirow{7}{*}{ South } & No. of observations & 258 & 497 & 370 & 337 \\
\hline & No. of country-years & 14 & 25 & 15 & 13 \\
\hline & Observed wage cuts & 0 & 5 & 4 & 19 \\
\hline & Incidence of wage cuts & 0 & 0.0101 & 0.0108 & 0.0564 \\
\hline & Fraction of wage cuts prevented & 1 & 0.447 & 0.485 & 0.358 \\
\hline & Fraction of industry-years affected & 0.005 & 0.008 & 0.010 & 0.031 \\
\hline & Probability of significance & 0.252 & 0.105 & 0.098 & 0.019 \\
\hline
\end{tabular}

Note: See Table 1

their possibility of avoiding a nominal wage cut. Thus, one would expect considerable rigidity in the Nordic countries, where both union density and bargaining coverage are high, while EPL is fairly strict (with the exception of Denmark). One would also expect considerable rigidity in southern Europe, as EPL is very strict and bargaining coverage fairly high, even if union density is on the low side. In the Core region, even if bargaining coverage is fairly high, and EPL fairly strict, union density is lower than in the Nordic countries, and EPL is less strict than in the South, so one would expect some, but weaker DNWR. Finally, in the Anglo countries, density is lower and EPL weaker than in the other regions, so this is where one would expect the weakest DNwR. In section 5 below, we analyse the effect of the institutional variables further.

In Table 3, we report results from splitting the sample by combining regions and sub-periods. 
Table 4: Results from 5000 simulations on countries.

\begin{tabular}{lccccccc} 
Country & $S$ & $T$ & $Y$ & $q$ & $F W C P$ & $(\hat{q}-q)$ & $p$ \\
\hline Austria & 408 & 26 & 2 & 0.0049 & 0.714 & 0.012 & 0.025 \\
Belgium & 575 & 26 & 31 & 0.0539 & 0.231 & 0.016 & 0.037 \\
Canada & 627 & 26 & 57 & 0.0909 & 0.077 & 0.008 & 0.269 \\
Denmark & 462 & 24 & 8 & 0.0172 & 0.463 & 0.015 & 0.033 \\
Finland & 368 & 23 & 2 & 0.0054 & 0.663 & 0.011 & 0.059 \\
France & 556 & 26 & 21 & 0.0378 & -0.200 & -0.006 & 0.869 \\
Germany & 665 & 26 & 16 & 0.0241 & 0.060 & 0.002 & 0.467 \\
Greece & 469 & 26 & 7 & 0.0149 & -0.129 & -0.002 & 0.723 \\
Ireland & 463 & 23 & 27 & 0.0583 & 0.325 & 0.028 & 0.015 \\
Italy & 312 & 13 & 0 & 0 & 1 & 0.010 & 0.037 \\
Luxembourg & 423 & 27 & 32 & 0.0757 & 0.269 & 0.028 & 0.023 \\
Netherlands & 483 & 27 & 23 & 0.0476 & 0.387 & 0.030 & 0.001 \\
New Zealand & 750 & 27 & 45 & 0.0600 & 0.216 & 0.017 & 0.037 \\
Norway & 674 & 27 & 2 & 0.0030 & 0.459 & 0.003 & 0.285 \\
Portugal & 411 & 18 & 3 & 0.0073 & 0.860 & 0.045 & 0.000 \\
Spain & 270 & 10 & 18 & 0.0667 & -0.053 & -0.003 & 0.649 \\
Sweden & 472 & 21 & 6 & 0.0127 & 0.469 & 0.011 & 0.037 \\
UK & 615 & 26 & 18 & 0.0293 & 0.217 & 0.008 & 0.130 \\
Us & 506 & 27 & 6 & 0.0119 & 0.308 & 0.005 & 0.231 \\
\hline
\end{tabular}

Note: $T$ is the number of years. See also Table 1

This implies a smaller number of observations behind each test statistic, and as expected this reduces the significance levels. It is nevertheless an interesting feature that the fraction of wage cuts prevented increased in the late 1990s in the Nordic countries, in contrast to the consistent reduction over time in the other three regions. The fraction of industry-years affected by DNWR has increased the Nordic region and the South, with a more mixed picture in the Anglo and the Core.

In Table 4, we report the results concerning individual countries. We observe that for all countries except Canada, France, Germany, Greece and Spain, the simulations indicate some DNWR, as some notional wage cuts are prevented ( $\mathrm{FWCP}>0.2)$. As these results are also based on fewer observations, the significance levels are lower. DNWR is, however, significant at the five percent level for Austria, Belgium, Denmark, Ireland, Italy, Luxembourg, the Netherlands, New Zealand, Portugal and Sweden, and Finland at the ten percent level. It is noteworthy that the fraction of wage cuts prevented is above 45 percent for all the Nordic countries. A surprising result is that the South splits in two, with strong DNWR in Portugal and Italy, and no DNwR in Spain and Greece. The fraction of industry-years affected by DNwR is highest in Portugal (4.5 percent) and the Netherlands (3 percent). 

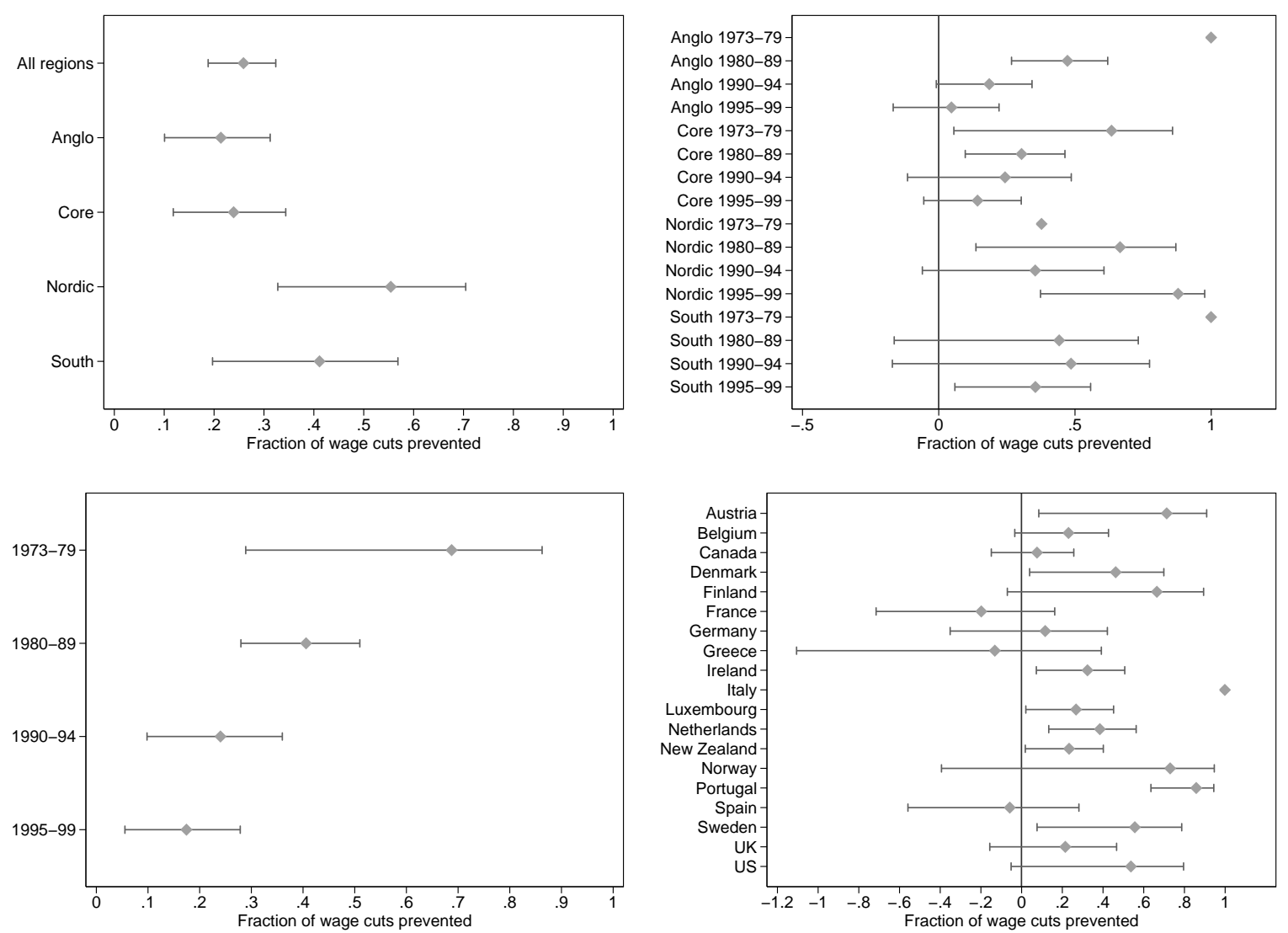

Figure 4: Estimated fractions of wage cuts prevented with 90\% confidence intervals.

To explore the precision of our measures of DNWR, we compute $90 \%$ confidence intervals for the fraction of wage cuts prevented based on the distributions from the simulations. Figure 4 presents these intervals for all the categories. The confidence intervals are fairly large, and with few exceptions, we are not able to conclude that the FWCP are significantly different from one another despite the variation between the estimates.

In view of the large uncertainty one should be careful when interpreting the differences between the countries. Nevertheless the estimates may be useful as a benchmark when comparing with estimates from micro studies. Figure 5 compares our estimates of the fraction of wage cuts prevented with those reported by Knoppik and Beissinger (2005) and by Dickens et al. (2006). As discussed in section 2 above, the extent of DNWR may differ between micro and industry data, and we shall return to this issue in section 5 below. Yet it is of interest to note that there is some correspondence across countries, with correlation coefficients of 0.65 and 0.25 , respectively. The outliers in both cases are Greece and France. For France, our low estimate is consistent with Biscourp et al. (2004), who find considerable wage flexibility in France. For Greece, on the other hand, our negative estimate seems questionable. Indeed, our estimate based on country-specific underlying distributions reported below, is much closer to the micro estimates, equal to 0.27 , although it is not significant. For the Us, Lebow et al. (2003) estimate 

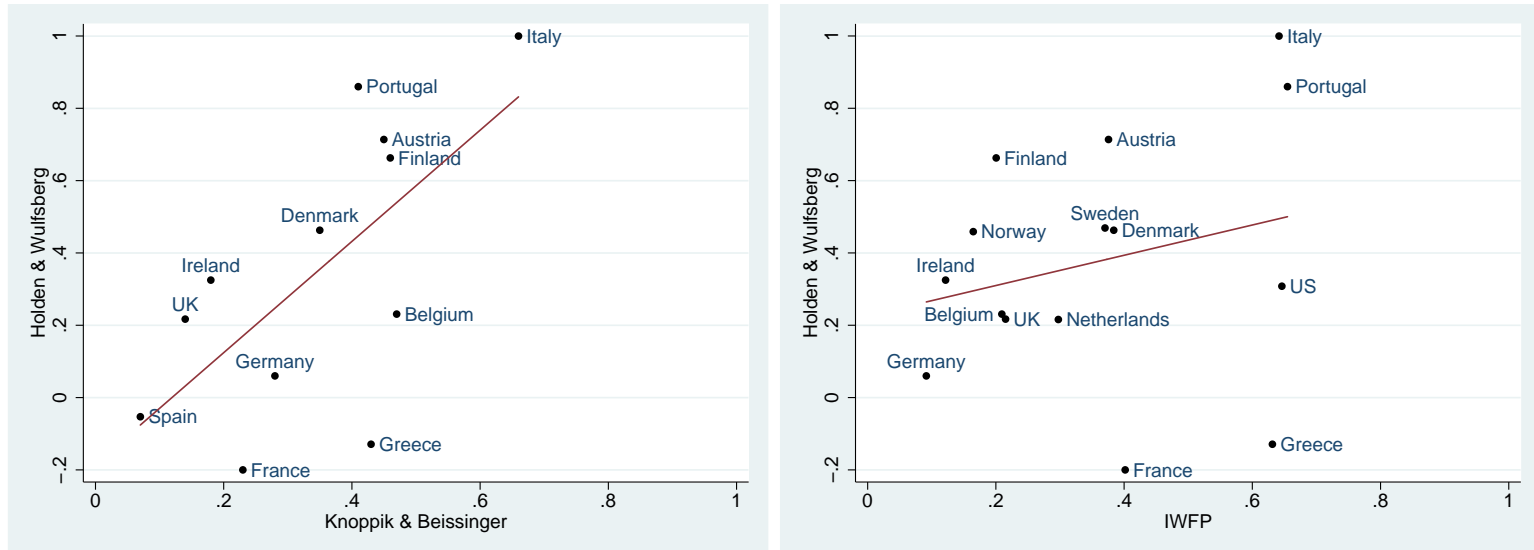

Figure 5: Comparing our estimates of $\mathrm{FWCP}$ with Knoppik and Beissinger (2005) (left) and with Dickens et al. (2006) (right).

the fraction of wage cuts prevented to about one half is between the two estimates, although somewhat closer to Dickens et al. (2006). Interestingly, our finding of strong DNWR for Portugal is consistent with the institutional feature that a nominal wage cut for a job stayer is illegal in Portugal.

\subsection{Robustness}

We explore the robustness of our findings in a number of different directions. To test our maintained assumption of a common shape for the wage change distributions across countries and years, we apply a Kolmogorov-Smirnov test. Concretely, we test for the equality between the common underlying distribution against alternatives where the underlying distribution is constructed separately for each country, and where it is constructed separately for each of the four time periods. The assumption of a common underlying distribution passes easily in all $19+27=46$ tests with the lowest p-value of 0.211 .

Nevertheless, we also perform our method with a number of alternative ways of constructing the underlying distribution. Figure 6 shows that the estimates from the main specification are rather similar to estimates based on country-specific underlying distributions, and highly similar to those based on period-specific underlying distributions. More precisely, we have constructed separate underlying distributions $\Delta w_{s}^{u}$ based on all observations for each country, alternatively for each period, and then proceeded with the method as before. Because the underlying distributions are based on fewer observations, without explicit selection of high wage growth samples, one would expect this method to be more vulnerable to a downward bias by DNWR compressing the underlying and notional distributions. Indeed, we find somewhat less DNWR, with overall FWCP of 18 percent (country-specific) and 20 percent (period-specific), see Table B1 in Appendix B). 

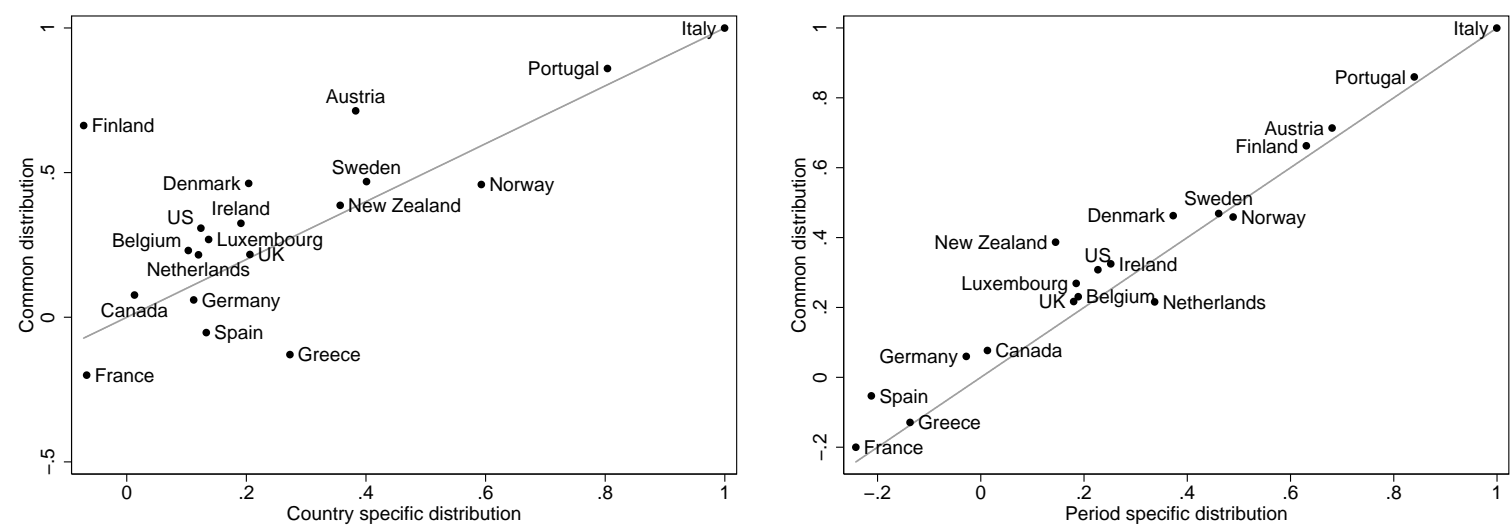

Figure 6: Comparing the estimates of FWCP using a common underlying distribution with country specific distributions (left) and periodic specific distributions (right).

The selection of samples for the underlying distribution, where we used 66 samples with high median nominal and real wage growth, is clearly somewhat arbitrary. Thus, we have also performed the method with the underlying distribution based on observations from countryyears with inflation above 5 percent in one specification and from country-years before 1993 in another, with results very similar to the period-specific results.

Finally, we have performed the method with a symmetry assumption inspired by Lebow et al. (1995) and Card and Hyslop (1997), where observations below the median in all countryyears are replaced by observations from the upper half of the distributions. Thus, all countryyear samples are symmetric, but the distributions differ across country-years according to the part above the median of the country-year specific empirical distributions. The results turned out to be very similar to the results from the main specification, cf. Table B1. The estimated FWCP are however somewhat lower, consistent with a possible downward bias of the symmetry approach, if DNWR makes firms compress wage increases, as suggested by Elsby (2006).

Observe that the symmetry approach involves no assumptions across country-year samples. In contrast, the main approach makes no assumptions regarding symmetry. This implies that these two approaches are based on orthogonal assumptions. In our view, our finding of very similar results from two orthogonal approaches is strong evidence in favour of the robustness of our results.

As noted above, there is a possible downward bias in our method, if DNwR despite our precautions have compressed the underlying distribution or inter percentile ranges in some country-years. One way of exploring the quantitative importance of this bias is to contaminate the data by adding DNWR, and then see to what extent we are able to detect the DNwR that we have added. If the downward bias is severe, we would presumably detect much less DNwR than we have added. Specifically, we pick ten countries evenly from the four regions (Belgium, 
Table 5: The effect from contaminating the data by adding DNWR.

\begin{tabular}{lcclccc}
\multicolumn{2}{c}{ Countries without additional DNWR } & & \multicolumn{3}{c}{ Countries with additional DNWR } \\
\cline { 1 - 2 } \cline { 5 - 6 } & $\Delta Y$ & $\Delta \mathrm{FWCR}$ & & & $\Delta Y$ & $\Delta \mathrm{FWCR}$ \\
\hline Austria & 0.000 & -0.007 & & Belgium & -0.484 & -0.421 \\
Italy & 0.000 & 0.000 & & Canada & -0.491 & -0.472 \\
Luxembourg & 0.000 & 0.001 & & Denmark & -0.500 & -0.495 \\
Netherlands & 0.000 & 0.002 & & Finland & -0.500 & -0.501 \\
New Zealand & 0.000 & -0.003 & & France & -0.476 & -0.460 \\
Norway & 0.000 & -0.022 & & Germany & -0.500 & -0.500 \\
Spain & 0.000 & 0.006 & & Greece & -0.429 & -0.430 \\
Sweden & 0.000 & 0.000 & & Ireland & -0.481 & -0.481 \\
UK & 0.000 & 0.001 & & Portugal & -0.333 & -0.329 \\
& & & & US & -0.500 & -0.497 \\
\hline
\end{tabular}

Notes: $\Delta Y$ is the contamination of the data in the form of the relative change in the number of nominal wage cuts. $\triangle \mathrm{FWCR}$ is the resulting percentage change in the fraction of wage cuts realised. An exact test would yield a $\triangle F W C R$ identical to $\Delta Y$ for each country.

Canada, Denmark, Finland, France, Germany, Greece, Ireland, Portugal and the us), and by random selection we eliminate half of the nominal wage cuts in each country by setting the associated nominal wage change to zero, thereby reducing the number of wage cuts from 324 to 238. Due to integer restrictions, we in practice eliminate 48 percent of the nominal wage cuts (in Portugal we eliminate one out of three observed wage cuts). Again, we apply our procedure with the contaminated data. With a perfect method, this would reduce the fraction of wage cuts realised (which is equal to one minus the fraction of wage cuts prevented) by on average 48 percent in these countries, without affecting the fraction of wage cuts realised in the other countries.

The results are promising. For the affected countries, the average fraction of wage cuts realised is reduced by 46 percent, as compared to the original results, see Table 5 . Taken at face value, these results suggest that our method on average is able to detect 96 percent of the total DNWR in the data (calculated as the computed reduction of 46 percent as compared to the constructed reduction of 48 percent, where $46 / 48=0.96$ ). The variation among the ten countries is fairly small, varying from a minimum of $42.1 / 48.4=87$ percent for Belgium to a maximum of 100 percent for Finland, Germany, Greece and Ireland. For the other countries, the fraction of wage cuts realised is hardly affected (on average, it decreases by 0.3 percent, with a maximum of 2.2 percent for Norway). These results suggest that there is some downward bias in the estimated DNWR due to DNWR affecting the notional distribution and/or the interpercentile ranges, but that the effect is not large.

A further point is to what extent our findings can be caused by downward real wage rigidity (DRWR). Bauer et al. (2003) and Barwell and Schweitzer (2004) find evidence for DRWR in Germany and the UK, respectively, while Dickens et al. (2006) find DRWR for all the 16 OECD 
countries they study. Furthermore, Bauer et al. (2003) point out that by not allowing for DRWR, there is a risk that the extent of DNWR is overestimated. In our data, however, almost 30 percent of all observations are negative real wage changes, by itself a clear sign that if DRWR exists, it is certainly not absolute.

It is hard to distinguish between DNWR and DRWR, in particular on industry data, where random components will imply that we are unlikely to find sharp effects exactly at the threshold points of zero nominal and real growth. In a companion paper, Holden and Wulfsberg (2007), we address the issue more thoroughly. Here, we limit ourselves to a simple exercise to shed light on the possible quantitative effects of DRWR on our results. Concretely, we add DRWR to our data set by randomly eliminating 20 percent of all observations of real wage cuts (i.e. 618 observations) by setting the associated nominal wage change equal to the rate of inflation. This reduces the total number of nominal wage cuts by 18 percent, from 324 to 265, with potentially strong impact on any findings of DNwR. However, applying our method with the manipulated data, it turns out that our measure of DNWR is not much affected: Eliminating real wage cuts involves a compression of the notional wage change distributions, implying that the overall fraction of wage cuts prevented increases by only four percentage points (from 26 to 30 percent). Thus, we conclude that while DRWR may have affected our results, it seems unlikely that the effect is large, in view of the fact that a fairly strong DRWR of 20 percent had a very limited impact on our results.

\section{Explaining the number of wage cuts}

While the previous analysis documents the existence of DNWR, it does not investigate explicitly whether the incidence of nominal wage cuts depends on economic and institutional variables. As mentioned above, Holden (2004) shows that DNWR is likely to depend on inflation in a nonlinear way, as well as on institutional variables like the strictness of the employment protection legislation (EPL) and union density or bargaining coverage. Furthermore, high unemployment may also weaken workers' resistance to nominal wage cuts. Thus, we apply a Poisson regression model of the number of wage cuts in each country-year sample, $Y_{i t}$, as the dependent variable (i.e. 449 observations) and with a number of explanatory variables including inflation and inflation squared, an index of EPL, union density, the unemployment rate. Regrettably, the data for institutional variables apply to the whole economy, and not to specific industry sectors. As variation in, for example, density or coverage in other parts of the economy would affect the density and coverage variable, but presumably not affect wage setting in the industry sector, the estimates of these variables might be biased downwards. On the other hand, if we do find an effect, it seems likely that this is due to the data capturing what we are after. 
We do the analysis in two different ways. First, we allow the number of observed wage cuts within a country-year to depend on the number of observations (industries) in the country-year sample, $S_{i t}$, thus estimating the effect of the explanatory variables on the empirical incidence rate of wage cuts. In the absence of DNWR, the institutional variables should not be able to explain the variation in the incidence rate. Second, we allow the number of observed wage cuts within a country-year to depend on the number of notional wage cuts, $\widehat{Y}_{i t}$, thus estimating the effect of the explanatory variables on the fraction of notional wage cuts that are actually realised. Adding institutional variables as regressors, we can then test directly whether these variables lead to fewer observed than notional wage cuts, i.e. to DNWR.

The conditional density in a Poisson model is

$$
f\left(Y_{i t}=y_{i t} \mid \mathbf{x}_{i t}\right)=\frac{e^{-\lambda_{i t}} \lambda_{i t}^{y_{i t}}}{y_{i t} !}
$$

and

$$
\ln \lambda_{i t}=\mathbf{x}_{i t}^{\prime} \boldsymbol{\beta}
$$

where $E\left(Y_{i t} \mid \mathbf{x}_{i t}\right)=\lambda_{i t}, \mathbf{x}_{i t}$ represents the explanatory variables and $\boldsymbol{\beta}$ is the parameter vector. However, as the maintained hypothesis in the Poisson model of no overdispersion is rejected, we use a negative binomial regression model, which allows for overdispersion and can be seen as a generalisation of the Poisson model. ${ }^{7}$ Specifically, we use two alternative specifications for the Poisson parameter:

$$
\begin{array}{ll}
\ln \lambda_{i t}=\mathbf{x}_{i t}^{\prime} \boldsymbol{\beta}+\varepsilon_{i t}, & \varepsilon_{i t} \sim \Gamma(1, \delta) \\
\ln \lambda_{i t}=\mathbf{x}_{i t}^{\prime} \boldsymbol{\beta}+\varepsilon_{i t}, & \varepsilon_{i t} \sim \Gamma\left(1, \phi_{i} e^{-\alpha_{i}}\right)
\end{array}
$$

Including a Gamma distributed error term, $\varepsilon_{i t}$, in $\left(7^{\prime}\right)$ and $\left(7^{\prime \prime}\right)$ allows the variance to mean ratios of $Y_{i t}$ to be larger than unity. (6) and ( $\left.7^{\prime}\right)$ together yield the pooled negative binomial regression model. In (7"), we also include a country specific fixed effect, $\alpha_{i}$, to allow for a country specific variance to mean ratio, see Hausman et al. (1984) for details.

The results of the negative binomial model (where we explain the incidence of wage cuts) are presented in the first two columns of Table 6. In accordance with the theoretical predictions, EPL, union density and inflation, all have a significant negative effect on the incidence of nominal wage cuts, although union density is not significant in the pooled specification. High unemployment increases the incidence of wage cuts.

The quantitative impact of the institutional variables is fairly large, even if the effects differ

\footnotetext{
7'Overdispersion' means that the variance in the data is greater than the mean, in contrast to the Poisson assumption that the variance and the mean are equal. Using a goodness-of fit test from a Poisson regression of $Y_{i t} / S_{i t}$, we reject no overdispersion with $\chi^{2}(416)=634.6$.
} 
Table 6: Maximum likelihood estimates with standard errors in parenthesis from negative binomial regressions in columns one and two and from Poisson regressions in columns three and four.

\begin{tabular}{|c|c|c|c|c|}
\hline & \multicolumn{2}{|c|}{ Incidence of wage cuts } & \multicolumn{2}{|c|}{ Fraction of wage cuts realised } \\
\hline & Pooled & Fixed effects & Pooled & Fixed effects \\
\hline $\operatorname{Ln}\left(S_{i t}\right)$ & $1(-)$ & $1(-)$ & - & - \\
\hline Ln(Simulated cuts) & - & - & $1(-)$ & $1(-)$ \\
\hline EPL & $-0.291^{*}(0.101)$ & $-0.716^{*}(0.196)$ & $-0.104(0.059)$ & $-0.430(0.293)$ \\
\hline Union density & $-0.606(0.585)$ & $-1.676(0.964)$ & $-0.966^{*}(0.377)$ & $-2.125(1.423)$ \\
\hline Inflation & $-0.505^{*}(0.073)$ & $-0.364^{*}(0.062)$ & $-0.096^{*}(0.048)$ & $-0.041(0.063)$ \\
\hline Inflation squared & $0.017^{*}(0.003)$ & $0.012^{*}(0.003)$ & $0.004(0.002)$ & $0.003(0.003)$ \\
\hline Unemployment & $0.109^{*}(0.029)$ & $0.093^{*}(0.036)$ & $0.033^{*}(0.016)$ & $0.008(0.036)$ \\
\hline constant & $-1.987^{*}(0.454)$ & $1.519 *(0.762)$ & $0.118(0.243)$ & - \\
\hline log-likelihood & -360.9 & -287.5 & -257.5 & -209.0 \\
\hline Number of observations & 422 & 409 & 282 & 278 \\
\hline
\end{tabular}

Notes: (i) $S_{i t}$ is the number of industries in country-year sample it. (ii) * indicates significance at $5 \%$ level. (iii) Luxembourg is not included because of lack of EPL data. In addition, Italy is excluded from the fixed effects models as there are no observed wage cuts in this country. (iv) There are fewer observations in column 3 and 4 because the fraction of wage cuts realised are not defined in 140 country-years where the notional incidence rate is zero.

according to the method applied. Using the point estimates from the fixed effects model, a reduction in the EPL index by 1.5 units, from the strict level in Portugal to the medium level of Austria or Sweden, would increase the incidence of nominal wage cuts by a factor of $\exp (-0.716(-1.5))=2.9$. This would raise the incidence of wage cuts in Portugal from 0.7 percent to 2.0 percent. A reduction in union density in Denmark from 75 percent down to 25 percent (as in Germany and the Netherlands) is associated with an increase in the incidence rate from 1.7 to 3.9 percent. A reduction in union density of 20 percentage points, as experienced in the UK from the late 1970s to the late 1990s, implies an increase in the incidence rate by a factor of 1.4 .

We then investigate whether institutions affect the extent of DNWR as measured by the average fraction of wage cuts realised $(Y / \widehat{Y})$, by a Poisson regression of $Y_{i t}$ normalised on the number of simulated wage cuts $\widehat{Y}_{i t}$. The results are presented in columns 3 (pooled) and 4 (fixed effects) of Table 6 . Note that in this case the restriction imposed by the Poisson regression relative to the negative binomial regression is accepted easily; indeed the results are the same in the negative binomial model for both specifications. ${ }^{8}$ In the pooled regression, we find a significant negative effect of EPL (although only at the ten percent level) and union density on the fraction of wage cuts realized, implying a positive effect on the fraction of wage cuts prevented. Unemployment has a negative effect on the fraction of wage cuts prevented.

\footnotetext{
${ }^{8}$ The goodness-of-fit test yields $\chi^{2}(410)=280.9$.
} 
Using the estimates from the pooled model, a reduction in the EPL index by 1.5 units would raise the fraction of wage cuts realised by a factor of $1.2(=\exp (-0.104(-1.5)))$. In the case of Sweden, this would imply an increase in the fraction of wage cuts realised from 52.8 to 61.7 percent, i.e. reducing the fraction of wage cuts prevented from 47.2 to 38.3 percent. Similarly, a reduction in union density from 75 percent to 25 percent would raise the fraction of wage cuts realised by a factor of $1.6(=\exp (-0.966(-0.5)))$; for Finland, the fraction of wage cuts realised would increase from 33.8 to 54.8 percent.

We have also included other institutional variables: bargaining coverage, temporary employment, and indices of centralisation and coordination, as suggested by Dessy (2002). However, these variables generally had much lower explanatory power than the variables that are included in Table 6. Adding a time trend in the regressions in Table 6 gave positive significant coefficients in the models for the incidence of wage cuts, but not in the models for the fraction of wage cuts realised. The trend coefficient in the fixed effects model is 0.065 , implying that the predicted change in the incidence of wage cuts over a period of 27 years is an increase by a factor of $5.8(=\exp (0.065(27)))$. The overall increase was, however, much greater; as shown in Table 1, the incidence of wage cuts increased from 0.23 percent in the 1970 s to 9.15 percent in the late 1990s. Overall, these results indicate that the reduction in DNwR over time (as measured by FWCP) is explained by the evolution of the economic and institutional variables, while there may have been an additional reduction over time in the incidence of wage cuts.

Interestingly, these results are in contrast to recent evidence based on microeconomic data reported in Dickens et al. (2006), where one finds weak and insignificant effect of EPL on DNWR, while union density in fact has a negative effect on DNwR, although only significant at the 10 percent level. ${ }^{9}$ While our analysis does not shed light on why Dickens et al. (2006) do not find any effect of EPL and unions on DNWR for individual workers, our discussion in section 2 above does suggest that EPL and unions will have stronger effect on DNWR in industry wages, exactly like we find in the Poisson regressions above. The reason for this is that the industry effect of DNWR for individual workers might be undone if there is flexible wage setting for other workers or in other firms. However, in country-years with strict EPL and unions, wage setting is unlikely to be that flexible. For example, a firm for which wages are set in a union contract would in most cases be unable to circumvent wage rigidity by replacing high wage workers with workers with lower wages.

\footnotetext{
${ }^{9}$ Dickens et al. (2006) find that union density is positively associated with DRWR, significant at the 10 percent level.
} 


\section{Conclusions}

Based on a novel method, we document the existence of downward nominal wage rigidity (DNWR) for manual workers in 19 OECD countries, over the period 1973-1999, using data for hourly nominal wages at industry level. Overall, we find that one out of four of the wage cuts that should have taken place under complete flexibility (notional wage cuts), have been prevented by DNWR, while slightly more than one percent of all industry-year observations have been affected by binding DNWR. To explore the robustness of our results, we have undertaken a number of different specifications of the key assumptions, with qualitatively the same results. Our method has also been successful in tests with various forms of 'contaminated data'.

Our paper makes three main contributions to the literature on DNWR. A number of recent micro studies, for many different countries, have documented that individual wages for job stayers are rigid downwards. However, the aggregate effects are disputed. One possible reason for this is that compositional changes at the firm or industry level may undo wage rigidities at the individual level. Indeed, this view is consistent with the findings of Fares and Lemieux (2000) and Card and Hyslop (1997); the latter find evidence of DNWR on Us micro data, but inconclusive evidence for state level data. By documenting the existence of DNWR at industry level data, we show that firm behaviour and market mechanisms may diminish, but do not remove, rigidity at individual level. In this sense we view our study as complementary to the increasing number of micro studies of DNWR.

Second, we explore whether the extent of DNWR can be explained by economic and institutional variables. We find that stricter employment protection legislation (EPL) and higher union density lead to stronger DNWR: in country-year samples with strict EPL and high union density, the incidence of nominal wage cuts is reduced significantly. The estimated effects of the institutional variables that we find is fairly strong. For example, weakening the EPL from a strict to a medium level, would, according to the point estimates, raise the incidence of nominal wage cuts in Portugal from 0.7 to 2.3 percent. A similar change in the EPL in Sweden, from its current medium level down to the less strict level of the UK, would imply an increase in the fraction of wage cuts realised from 52.8 to 61.7 percent, i.e. reducing the fraction of wage cuts prevented from 47.2 to 38.3 percent. Thus, our results suggest that changing labour market institutions would have considerable impact on wage rigidities.

The effect of institutional variables is consistent with differences in DNWR across countries. Splitting into groups of countries, we find stronger DNWR in two groups, the South (Italy, Greece, Portugal, Spain) and the Nordic region (Denmark, Finland, Norway and Sweden), where EPL is stricter and/or unions are stronger than in the other groups; the Core (Austria, Belgium, France, Germany, Luxembourg, Netherlands), and the Anglo region (Canada, Ireland, New Zealand, the UK and the Us). 
These findings are also important from a theoretical point of view, as they strengthen the case for DNWR in part being caused by contracts and institutional features, as argued by MacLeod and Malcomson (1993) in a individual bargaining framework, and Holden (1994) in a collective agreement framework. Interestingly, the micro study of Dickens et al. (2006) does not find the same positive effect of EPL and union density on DNWR that we do. One possible explanation for this difference is if DNWR for individual workers can be undone by wage flexibility for other workers or in other firms, unless prevented by strict EPL and/or union contracts. For example, for a firm facing a union contract, it would be difficult to circumvent wage rigidities by replacing high wage workers by low wage workers. However, as we have not be able to test for fairness and morale explanations of DNWR, such hypotheses remain speculative. Furthermore, as argued by Holden (1994), these explanations are likely to be complementary in the sense that fairness and contract explanations may reenforce each other.

Third, we explore the change in DNWR over time. We find that DNWR in the form of the fraction of notional wage cuts that is prevented by DNWR, has fallen over time. For all countries together, the fraction of wage cuts prevented by DNWR has fallen from 60 percent in the 1970s to 16 percent in the late 1990s. The Nordic countries are an exception; for this group, the fraction of wage cuts prevented is highest in the late 1990s. Most of this reduction in DNWR can be explained by the change in economic and institutional variables, by less strict employment protection legislation, lower union density, and higher unemployment. However, in spite of the reduction in DNWR, the fall in inflation has implied that more industries are affected by DNWR. We find that the fraction of industry-years affected by DNWR has increased from 0.4 percent in the 1970s, to 1.7 percent in the late 1990s.

In an important paper, Barro (1977) argued that short run wage rigidity may reflect intertemporal risk sharing between the employer and an risk averse employee, with no allocative effects, i.e. no effects on employment decisions. On this argument, a finding of significant DNWR need not imply effects on employment and output. While we cannot rule out this argument, there are several reasons for why we still believe that DNWR in industry wages is likely to affect employment and output under low inflation. One reason is that in most OECD countries, the majority of workers have their wages set in collective bargaining, often at more centralised levels. Presumably, such wage rigidity, being largely exogenous to the firm, would affect firms' employment decisions, in particular as to hirings. This is reflected in the dominating explanations of OECD unemployment, where wage setting and labour market institutions play a key role (Layard et al., 1991 and Nickell et al., 2005). On this basis, one would expect that increased wage pressure due to binding DNWR would lead to higher unemployment. A second reason is that several recent contributions have argued that wage rigidity is a necessary and important 
piece in explanations of business cycle fluctuations, see e.g. Erceg et al. (2000), Smets and Wouters (2003), Shimer (2004) and Hall (2005), the latter two explicitly discussing Barro's argument. In an era of low inflation, the existence of DNWR would exacerbate wage stickiness in a downturn of the economy, presumably amplifying the effect on vacancies and employment. A third reason is that binding DNWR would presumably also push up prices, leading to higher inflation than we would otherwise observe. In most OECD countries, higher inflation will be met by higher real interest rates, which would have a short run dampening effect on output and employment.

In spite of these arguments, the effect of DNWR on employment and output is clearly an empirical issue of great interest for future research. In such work, we hope that our country-year specific estimates of DNWR may be useful.

Overall, our finding of DNWR yields clear additional support to the idea that DNWR has some, but moderate impact on firms' wage costs in many OECD countries, especially in Europe. Weaker employment protection legislation, lower union density, and higher unemployment have implied that the fraction of wage cuts prevented by DNWR has fallen over time. Yet the fraction of total industries that have been affected by DNWR has increased over time, due to the lower rates of inflation and lower nominal wage growth in recent years.

\section{References}

Agell, J. and Lundborg, P. (2003). Survey Evidence on Wage Rigidity and Unemployment. Scandinavian Journal of Economics, 105, 15-30.

Akerlof, G., Dickens, W., and Perry, W. (1996). The Macroeconomics of Low Inflation. Brookings Papers on Economic Activity, 1:1996, 1-76.

Altonji, J. and Devereux, P. (2000). The Extent and Concequences of Downward Nominal Wage Rigidity. In S. Polachek (Ed.), Worker Well-Being, number 7236. Elsevier.

Barro, R. (1977). Long-Term Contracting, Sticky Prices, and Monetary Policy. Journal of Monetary Economics, 3(3), 305-316.

Barwell, R. and Schweitzer, M. (2004). The incidence of nominal and real wage rigidity in Great Britain: 1978-1998. Mimeo, Bank of England.

Bauer, T., Bonin, H., and Sunde, U. (2003). Real and nominal wage rigidities and the rate of inflation: Evidence from West German micro data. DP 959, IZA.

Bewley, T. (1999). Why Wages Do Not Fall During a Recession. Boston: Harvard University Press.

Biscourp, P., Dessy, O., and Fourcade, N. (2004). Downward wage rigidity: A micro level empirical analysis for France in the 90s. Mimeo, INSEE.

Blanchard, O. and Wolfers, J. (2000). The Role of Shocks and Institutions in the Rise of European Unemployment: The Aggregate Evidence. The Economic Journal, 110(462), C1C33. 
Blinder, A. and Choi, D. (1990). A Shred of Evidence of Theories of Wage Stickiness. Quarterly Journal of Economics, 105, 1003-1016.

Camba-Mendez G., Garcia J.A., Palenzuela D.A. (2003). Relevant economic issues con-cerning the optimal rate of inflation. Background Studies for the ECB's Evaluation of its Monetary Policy Strategy, ECB.

Cameron, A. and Trivedi, P. (1998). Regression Analyses of Count Data. Cambridge University Press.

Card, D. and Hyslop, D. (1997). Does Inflation Grease the Wheels of the Labor Market? In C. Romer and D. Romer (Eds.), Reducing Inflation: Motivation and Strategy (pp. 71-121). University of Chicago Press.

Christofides, L. and Leung, M. (2003). Nominal Wage Rigidity in Contract Data: A Parametric Approach. Economica, 70, 619-638.

Dessy, O. (2002). Nominal Wage Rigidity and Institutions: Micro-Evidence From the Europanel. Technical report, University of Milan.

Dickens, W., Goette, L., Groshen, E.L., Holden, S., Messina, J., Schweitzer, M.E., Turunen, J. and Ward, M. (2006). How wages change: Micro Evidence from the International Wage Flexibility project. ECD Working Paper No 697.

ECB (2003). Background Studies for the ECB's Evaluation of its Monetary Policy Strategy. Frankfurt am Main: European Central Bank.

Elsby, M. (2006). Evaluating the Economic Significance of Downward Nominal Wage Rigidity. NBER Working Paper No. 12611.

Erceg, C.J. and Henderson, D.W. and Levin, A.T. (2000) Optimal monetary policy with staggered wage and price contracts. Journal of Monetary Economics 46, 281-313.

Fehr, E. and Gotte, L. (2005). Robustness and Real Concequences of Nominal Wage Rigidity. Journal of Monetary Economics, 52(4), 779-804.

Fares, J and T. Lemieux (2000). Downward Nominal-Wage Rigidity: A Critical Assessment and Some New Evidence for Canada. Paper presented at the Bank of Canada conference Price Stability and the Long Run Target for Monetary Policy.

Fortin, P. and Dumont, K. (2000). The Shape of the Long-Run Phillips Curve: Evidence from Canadian Macrodata, 1956 - 97. Technical report, Canadian Institute for Advanced Research.

Gordon, R.J. (1996). Comment on Akerlof, Dickens and Perry: The Macroeconomics of Low Inflation. Brookings Papers on Economic Activity, 1 : 1996, 60-66.

Hall, R.E. (2005). Employment fluctuations with equilibrium wage stickiness. American Economic Review, 95(1), 50-65.

Hausman, J., Hall, B., and Z., G. (1984). Econometric Models for Count Data with an Application to the Patents-R\&D Relationship. Econometrica, 52(4), 909-938.

Holden, S. (1994). Wage Bargaining and Nominal Rigidities. European Economic Review, 38, 1021-1039. 
Holden, S. (1997). Wage bargaining, holdout and inflation. Oxford Economic Papers, 49, $235-255$.

Holden, S. (1998). Wage Drift and the Relevance of Centralised Wage Setting. Scandinavian Journal of Economics, 100, 711-731.

Holden, S. (2004). The Costs of Price Stability—Downward Nominal Wage Rigidity in Europe. Economica, 71, 183-208.

Holden S. and Wulfsberg F. (2007) Are real wages rigid downwards? Mimeo University of Oslo, Norges Bank

ILO (1997). World Labour Report 1997-98 Industrial Relations, Democracy and Social Stability. Technical report, International Labour Organization, http://www.ilo.org/public/ english/dialogue/ifpdial/publ/wlr97/summary.htm.

Kahn, S. (1997). Evidence of Nominal Wage Stickiness from Micro-Data. American Economic Review, 87(5), 993-1008.

Karanassou M., Sala H, Snower D.J. (2003). A reappraisal of the inflation-unemployment tradeoff. Mimeo, University of London

Knoppik, C. and Beissinger, T. (2003). How Rigid are Nominal Wages? Evidence and Implications for Germany. Scandinavian Journal of Economics, 105(4), 619-641.

Knoppik, C. and Beissinger, T. (2005). Downward nominal wage rigidity in Europe: An analysis of European micro data from the ECHP 1994-2001. DP 1492, IZA.

Layard, R., Nickell S. and Jackman, R. (1991) Unemployment. Oxford University Press.

Lazear, E. (1990). Job Security Provisions and Employment. Quarterly Journal of Economics, $105(3), 699-725$.

Lebow, D., Saks, R., and Wilson, B. (2003). Downward Nominal Wage Rigidity. Evidence from the Employment Cost Index. Advances in Macroeconomics, 3(1), Article 2. http: //www . bepress.com/bejm/advances/vol3/iss1/art2.

Lebow, D., Stockton, D., and Wascher, W. (1995). Inflation, nominal wage rigidity and the efficiencly of labor markets. Finance and Economics DP 94-45, Board of Governors of the Federal Reserve System.

MacLeod, W. and Malcomson, J. (1993). Investment, Holdup, and the Form of Market Contracts. American Economic Review, 37, 343-354.

Mankiw, N. (1996). Comment on Akerlof, Dickens and Perry: The Macroeconmics of Low Inflation. Brookings Papers on Economic Activity, 1:1996, 66-70.

McLaughlin, K. (1994). Rigid Wages? Journal of Monetary Economics, 34(3), 383-414.

Nickell, S., Nunziata, L. and Ochel, W. (2005). Unemployment in the OECD since the 1960s. What do we know? The Economic Journal, 115, 1-27.

Nickell, S. and Quintini, G. (2003). Nominal Wage Rigidity and the Rate of Inflation. Economic Journal, 113, 762-781.

OECD (2002). Economic Outlook. Paris: OECD. 
OECD (2004). Employment Outook. Paris: OECD.

Shimer, R. (2004). The Consequences of Rigid Wages in Search Models. Journal of the European Economic Association, 2(2-3), 469-479.

Smets, F. and Wouters, R. (2003). An estimated dynamic stochastic general equilibrium model for the Euro area. Journal of the European Economic Association 1, 5, 1123-1175.

Solon, G., Barsky, R. and Parker, J. (1994). Measuring the Cyclicality of Real Wages: How Important is the Composition Bias? Quarterly Journal of Economics 109(1), 1-25.

Svensson, L.E.O. (2001). Comment on Charles Wyplosz, 'Do We Know How Low Inflation Should Be?' In A. Herrero, V. Gaspar, L. Hoogduin, J. Morgan, and B. Winkler (Eds.), Why price stability (pp. 46-50). ECB, Frankfurt.

Tobin, J. (1972). Inflation and Unemployment. American Economic Review, 62, 1-18.

Wyplosz, C. (2001). Do we know how low inflation should be? In A. Herrero, V. Gaspar, L. Hoogduin, J. Morgan, and B. Winkler (Eds.), Why price stability (pp. 15-33). ECB, Frankfurt.

\section{A Data appendix}

We have obtained wage data from Eurostat for all countries except Austria, Canada, Finland, New Zealand Norway, Sweden and the us (see below). The precise source is Table HMwhour in the Harmonized earnings domain of under the Population and Social Conditions theme in the NEWCRONOS database. Our wage variable (HMWHOUR) is labelled Gross hourly earnings of manual workers in industry. Gross earnings cover remuneration in cash paid directly and regularly by the employer at the time of each wage payment, before tax deductions and social security contributions payable by wage earners and retained by the employer. Payments for leave, public holidays, and other paid individual absences, are included in principle, in so far as the corresponding days or hours are also taken into account to calculate earnings per unit of time. The weekly hours of work are those in a normal week's work (i.e. not including public holidays) during the reference period (October or last quarter). These hours are calculated on the basis of the number of hours paid, including overtime hours paid. Furthermore, we use data in national currency and males and females are both included in the data. The data for Germany does not include GDR before 1990 or new Länder.

The data are recorded by classification of economic activities (NACE Rev. 1). The sections represented are Mining and quarrying (C), Manufacturing (D), Electricity, gas and water supply (E) and Construction (F). We use data on various levels of aggregation from the section levels (e.g. D Manufacturing) to group levels (e.g. DA 159 Manufacturing of beverages), however, using the most disaggregate level available in order to maximize the number of observations. If for example, wage data are available for D, DA 158 and DA 159, we use the latter two only to avoid counting the same observations twice.

Wage data for Austria, Canada, Finland, New Zealand, Sweden and the us are from Table 5B 'Wages in manufacturing' in LABORstA, the Labour Statistics Database, ILO. The data are recorded by ISIC, Three digit level covering the same sectors as the Eurostat data. Wage data for Norway are from Table 210 National Accounts 1970-2003, Statistics Norway, recorded by NACE Rev. 1. The sections represented are the same as for the Eurostat data. 
The average number of observations per country-year sample is 20.5, with a standard error of 4.7. The distribution of the number of wage cuts relative to the number of observations on years and countries are reported in Table A1.

We have removed ten extreme observations from the sample.

Data for inflation and unemployment are from the OECD Economic Outlook database.

The primary sources for the employment protection legislation (EPL) index, which is displayed in Table A3, are OECD (2004) for the 1980-1999 period and Lazear (1990) for the years before 1980. We follow the same procedure as Blanchard and Wolfers (2000) to construct timevarying series which is to use the OECD summary measure in the 'Late 1980s' for 1980-89 and the 'Late 1990s' for 1995-99. For 1990-94 we interpolate the series. For 1973-79 the percentage change in Lazear's index is used to back-cast the OECD measure. However, we are not able to reconstruct the Blanchard and Wolfers data exactly.

Data for union density is from OECD. Data for Greece for 1978 and 1979 are interpolated while data before 1977 is extrapolated at the 1977 level.

Data for bargaining coverage is from OECD (2004, Table 3.5) which provide data for 1980, 1990 and 2000. Data for the intervening years are calculated by interpolation while the observations for 1980 are extrapolated backwards. Data for Greece and Ireland is only available for 1994 from ILO (1997, Table 1.2). This observation is extrapolated for the entire period.

The incidence of temporary employment is defined as the fraction of temporary to total employment. Data from 1983 is from OECD's Corporate Data Environment, Table Employment by permanency of the (main) job. Data for Finland 1995 and 1996 and Norway are from Eurostat. Data for Sweden are provided by the Statistics Sweden (SCB). Lacking information prior to 1983, we have chosen not to extrapolate the data. 


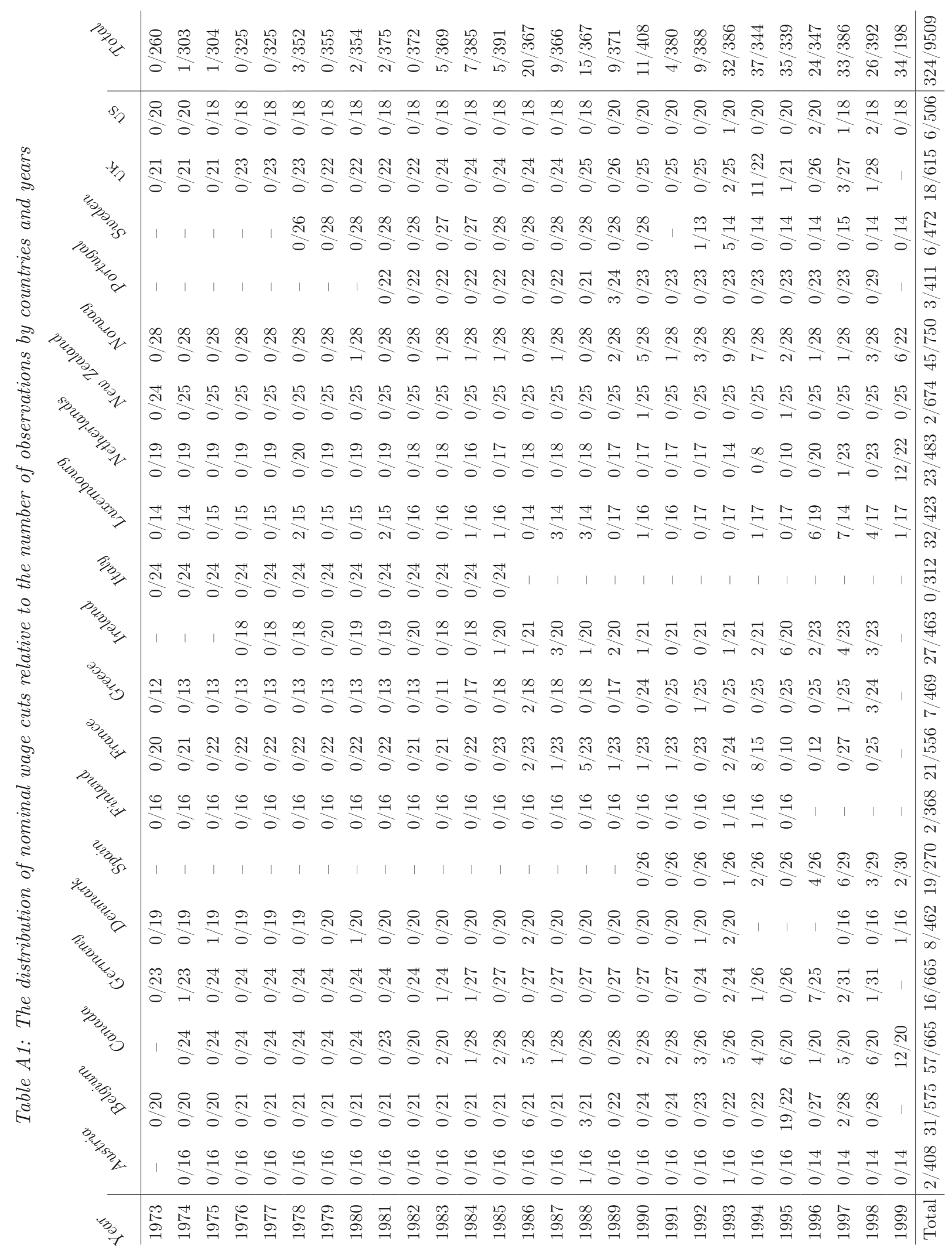




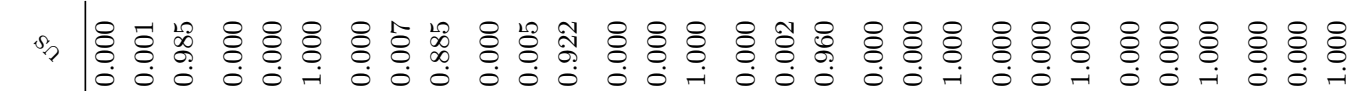

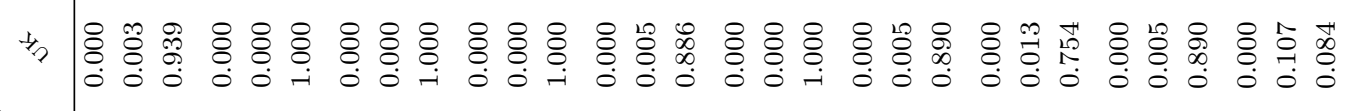

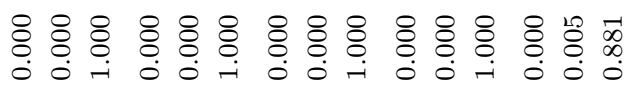

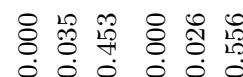

\% 3/ 纤, o \%

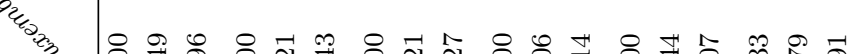

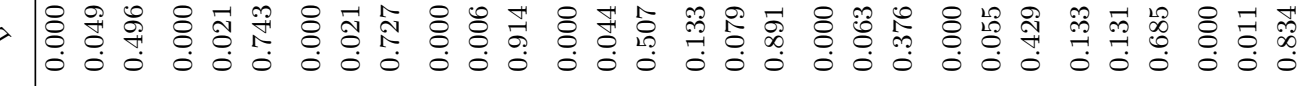
ß \& \& \& \& s, o o

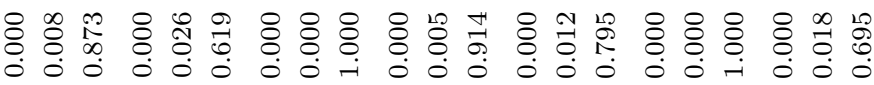

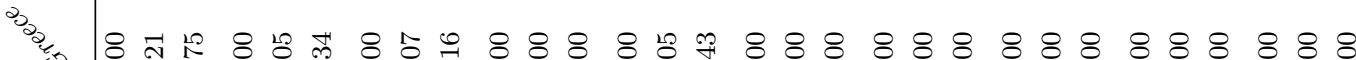

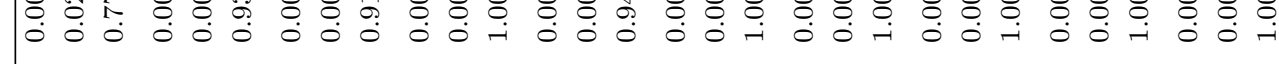

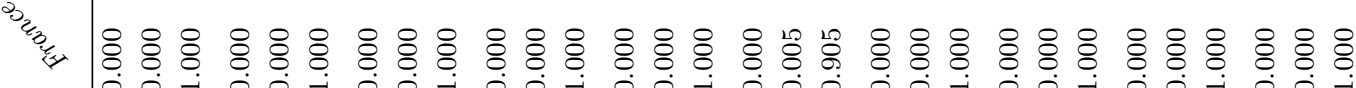
" $\xi_{3}^{2}$

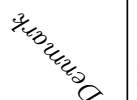
ह

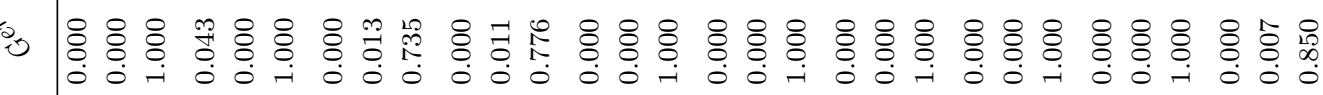

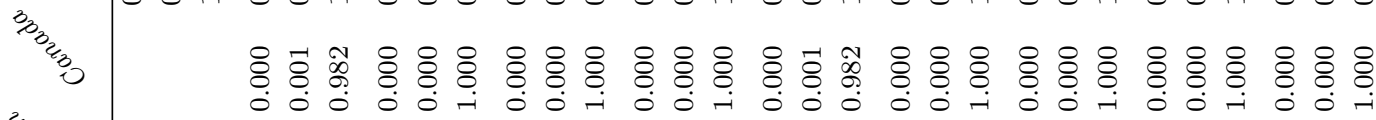
है,

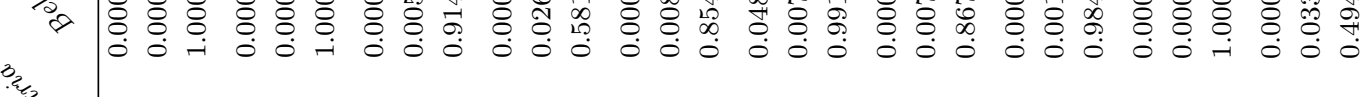

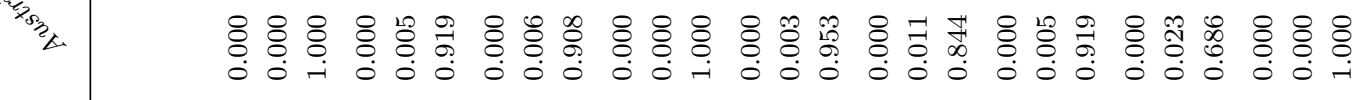

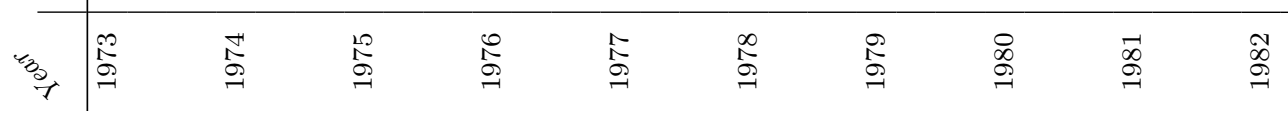




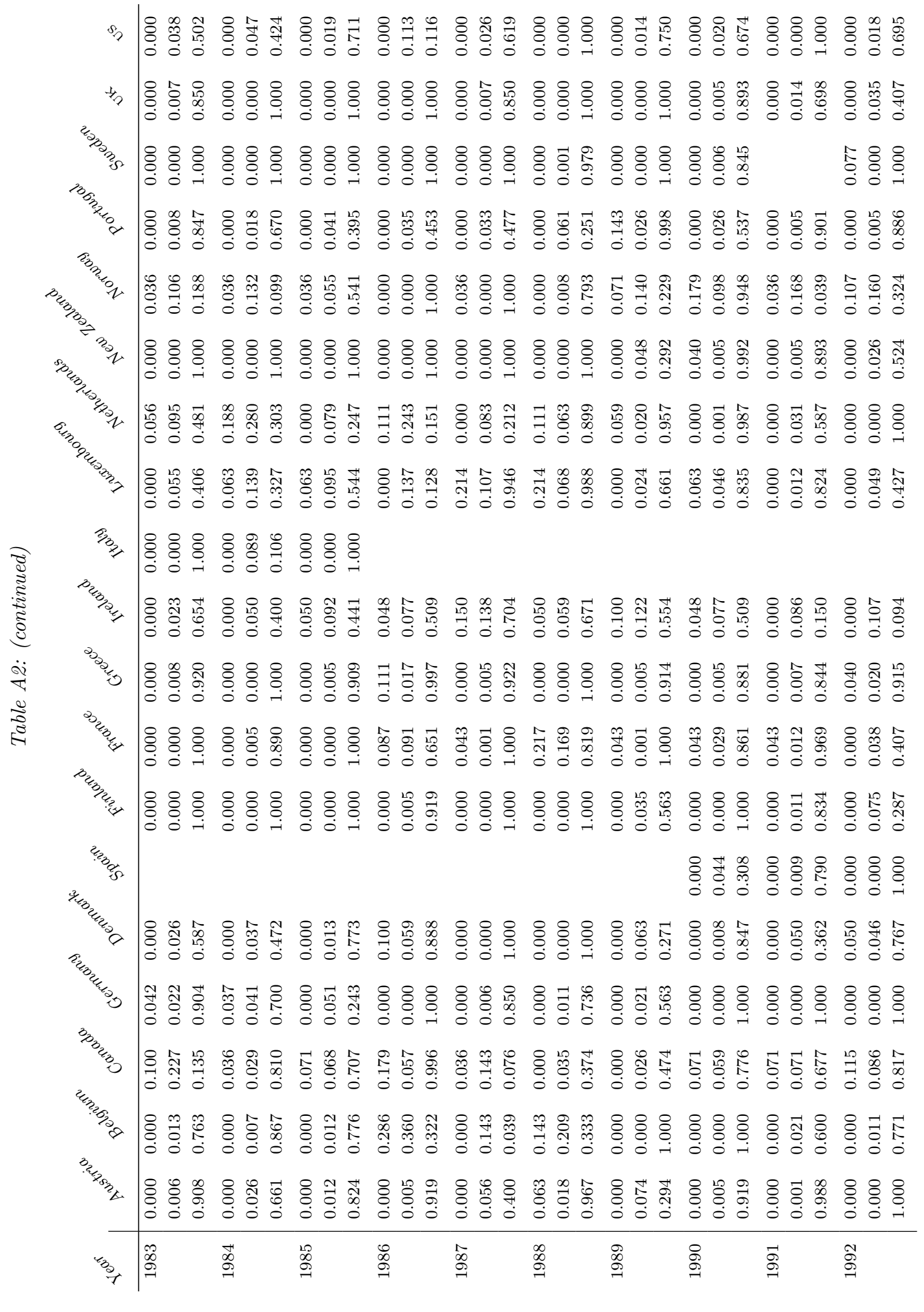




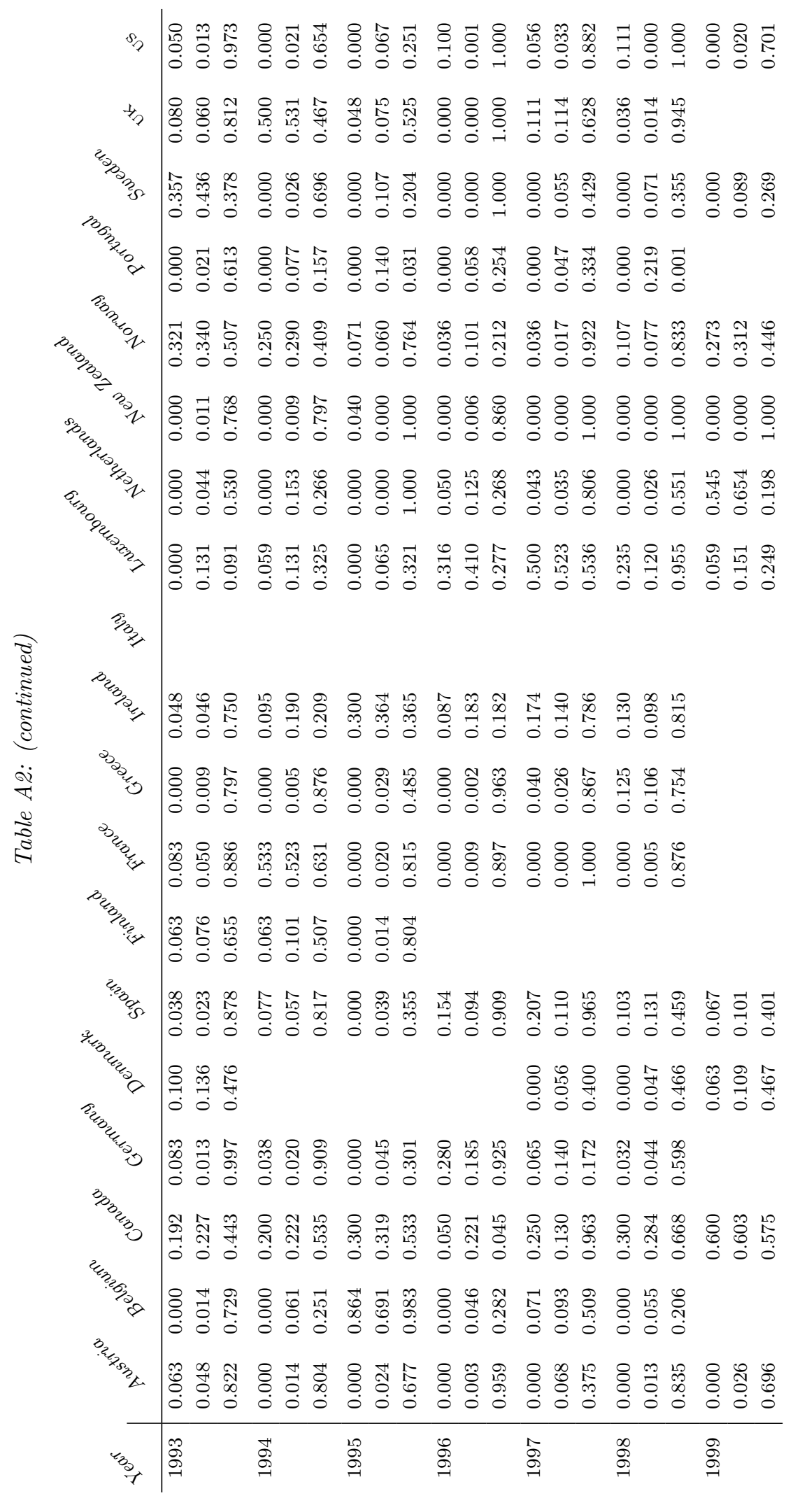


Table A3: Indices for employment protection legislation, EPL

\begin{tabular}{|c|c|c|c|c|c|c|c|c|c|c|c|c|c|c|c|c|c|c|}
\hline Year & $A T$ & $B E$ & $C A$ & $D E$ & $D K$ & $E S$ & $F I$ & $F R$ & $G R$ & $I E$ & $I T$ & $N L$ & NO & $N Z$ & $P T$ & $W$ & $U K$ & $U S$ \\
\hline 73 & 32 & 20 & 0.80 & 3.20 & 30 & 4.00 & 2.30 & 2.44 & 3.60 & 0.76 & 3.60 & 2.70 & 90 & 0 & .17 & & 56 & 20 \\
\hline 74 & 1.39 & 3.20 & 80 & 3.20 & 2.30 & 4.00 & 2.30 & 2.57 & 3.60 & 0.83 & 3.60 & 2.70 & 2.90 & 0.90 & 3.43 & 3.03 & 0.58 & 0.20 \\
\hline 75 & 1.47 & .20 & 0.80 & 3.20 & 30 & 4.00 & 2.30 & 2.70 & 3.60 & 0.90 & 3.60 & 2.70 & 2.90 & 0.90 & 3.68 & 3.50 & 0.60 & 0.20 \\
\hline 76 & 1.61 & 3.20 & 0.80 & 3.20 & 30 & 3.96 & 2.30 & 2.70 & 3.60 & 0.90 & 3.60 & 2.70 & 2.90 & 0.90 & 3.76 & 3.50 & 0.60 & 0.20 \\
\hline 1977 & 1.76 & 3.20 & 0.80 & 3.20 & 2.30 & 3.92 & 2.30 & 2.70 & 3.60 & 0.90 & 3.60 & 2.70 & 2.90 & 0.90 & 3.85 & 3.50 & 0.60 & 0.20 \\
\hline 1978 & 1.91 & 3.20 & 0.80 & 3.20 & 2.30 & 3.88 & 2.30 & 2.70 & 3.60 & 0.90 & 3.60 & 2.70 & 2.90 & 0.90 & 3.93 & 3.50 & 0.60 & 0.20 \\
\hline 79 & 2.05 & 3.20 & 0.80 & 3.20 & 2.30 & 3.84 & 2.30 & 2.70 & 60 & 0.90 & 3.60 & 2.70 & 2.90 & 0.90 & 4.02 & 60 & 0.60 & 0.20 \\
\hline 1980 & 2.20 & 3.20 & 0.80 & 3.20 & 2.30 & 3.80 & 2.30 & 2.70 & 3.60 & 0.90 & 3.60 & 2.70 & 2.90 & 0.90 & 4.10 & 50 & 0.60 & 0.20 \\
\hline 1981 & 2.20 & 3.20 & 0.80 & 3.20 & 2.30 & 3.80 & 2.30 & 2.70 & 3.60 & 0.90 & 3.60 & 2.70 & 2.90 & 0.90 & 4.10 & 3.50 & 0.60 & 0.20 \\
\hline 1982 & 2.20 & 3.20 & 0.80 & 3.20 & 2.30 & 3.80 & 2.30 & 2.70 & 3.60 & 0.90 & 3.60 & 2.70 & 2.90 & 0.90 & 4.10 & 3.50 & 0.60 & 0.20 \\
\hline 1983 & 2.20 & 3.20 & 0.80 & 3.20 & 2.30 & 3.80 & 2.30 & 2.70 & 3.60 & 0.90 & 3.60 & 2.70 & 2.90 & 0.90 & 4.10 & 3.50 & 0.60 & 0.20 \\
\hline 1984 & 2.20 & 3.20 & 0.80 & 3.20 & 2.30 & 3.80 & 2.30 & 2.70 & 3.60 & 0.90 & 3.60 & 2.70 & 2.90 & 0.90 & 4.10 & 0 & 0.60 & 0.20 \\
\hline 1985 & 2.20 & 3.20 & 0.80 & 3.20 & 2.30 & 3.80 & 2.30 & 2.70 & 3.60 & 0.90 & 3.60 & 2.70 & 2.90 & 0.90 & 4.10 & 3.50 & 0.60 & 0.20 \\
\hline 1986 & 2.20 & 3.20 & 0.80 & 3.20 & 2.30 & 3.80 & 2.30 & 2.70 & 3.60 & 0.90 & 3.60 & 2.70 & 2.90 & 0.90 & 4.10 & 0 & 0.60 & 0.20 \\
\hline 1987 & 2.20 & 3.20 & 0.80 & 3.20 & 2.30 & 3.80 & 2.30 & 2.70 & 3.60 & 0.90 & 3.60 & 2.70 & 2.90 & 0.90 & 4.10 & 3.50 & 0.60 & 0.20 \\
\hline 1988 & 2.20 & 3.20 & 0.80 & 3.20 & 2.30 & 3.80 & 2.30 & 2.70 & 3.60 & 0.90 & 3.60 & 2.70 & 2.90 & 0.90 & 4.10 & 3.50 & 0.60 & 0.20 \\
\hline 1989 & 2.20 & 3.20 & 0.80 & 3.20 & & 3.80 & 2.30 & 2.10 & & 0.90 & 3.60 & & 2.90 & & 4.10 & & 0.60 & 0.20 \\
\hline 1990 & 2.20 & 3.03 & 0.80 & 3.08 & 2.15 & 3.65 & 2.27 & 2.75 & 3.58 & 0.90 & 3.45 & 2.60 & 2.87 & 0.90 & 4.03 & 3.28 & 0.60 & 0.20 \\
\hline 1991 & 2.20 & 2.87 & 0.80 & 2.97 & 2.00 & 3.50 & 2.23 & 2.80 & 3.57 & 0.90 & 3.30 & 2.50 & 2.83 & 0.90 & 3.97 & 3.07 & 0.60 & 0.20 \\
\hline 1992 & 2.20 & 2.70 & 0.80 & 2.85 & 1.85 & 3.35 & 2.20 & 2.85 & 3.55 & 0.90 & 3.15 & 2.40 & 2.80 & 0.90 & 3.90 & 2.85 & 0.60 & 0.20 \\
\hline 1993 & 2.20 & 2.53 & 0.80 & 2.73 & 1.70 & 3.20 & 2.17 & 2.90 & 3.53 & 0.90 & 3.00 & 2.30 & 2.77 & 0.90 & 3.83 & 2.63 & 0.60 & 0.20 \\
\hline 1994 & 2.20 & 2.37 & 0.80 & 2.62 & 1.55 & 3.05 & 2.13 & 2.95 & 3.52 & 0.90 & 2.85 & 2.20 & 2.73 & 0.90 & 3.77 & 2.42 & 0.60 & 0.20 \\
\hline 1995 & 2.20 & 2.20 & 0.80 & 2.50 & 1.40 & 2.90 & 2.10 & 3.00 & 3.50 & 0.90 & 2.70 & 2.10 & 2.70 & 0.90 & 3.70 & 2.20 & 0.60 & 0.20 \\
\hline 1996 & 2.20 & 2.20 & 0.80 & 2.50 & 1.40 & 2.90 & 2.10 & 3.00 & 3.50 & 0.90 & 2.70 & 2.10 & 2.70 & 0.90 & 3.70 & 2.20 & 0.60 & 0.20 \\
\hline 1997 & 2.20 & 2.20 & 0.80 & 2.50 & 1.40 & 2.90 & 2.10 & 3.00 & 3.50 & 0.90 & 2.70 & 2.10 & 2.70 & 0.90 & 3.70 & 2.20 & 0.60 & 0.20 \\
\hline 1998 & 2.20 & 2.20 & 0.80 & 2.50 & 1.40 & 2.90 & 2.10 & 3.00 & 3.50 & 0.90 & 2.70 & 2.10 & 2.70 & 0.90 & 3.70 & 2.20 & 0.60 & 0.20 \\
\hline 1999 & 2.20 & 2.20 & 0.80 & 2.50 & 1.40 & 2.90 & 2.10 & 3.00 & 3.50 & 0.90 & 2.70 & 2.10 & 2.70 & 0.90 & 3.70 & 2.20 & 0.60 & 0.20 \\
\hline
\end{tabular}

Table A4: Trade union density, percent

\begin{tabular}{|c|c|c|c|c|c|c|c|c|c|c|c|c|c|c|c|c|c|c|c|}
\hline$a r$ & $T$ & $B E$ & $C A$ & $E$ & $K$ & $E S$ & $F I$ & $F R$ & i & $I E$ & $I T$ & $U$ & $N L$ & $O$ & $Z$ & $T$ & W & IK & $S$ \\
\hline 73 & 8 & .6 & 60 & 2.4 & 62.2 & & 4 & 2.1 & 8 & 3 & 3 & 5.0 & 2 & 2 & .18 & & & .5 & 3.50 \\
\hline 74 & & .0 & 00 & 7.7 & .2 & & 2 & .7 & 8 & 9 & 2 & 5.6 & 0 & .1 & 9.12 & & & 4 & 20 \\
\hline 1. & & .8 & 3.30 & 6 & .9 & & & 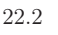 & & & & & & & & & & & \\
\hline 976 & & 2.6 & 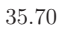 & 6.1 & 0 & & & 21.4 & 5.8 & 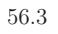 & 50 & 46.7 & & 52.8 & & & & 49.4 & 1.60 \\
\hline 77 & 6 & 53.5 & 36.50 & 5.2 & 74.1 & & 66.4 & 21.4 & 5.8 & 57.0 & 49.8 & 47.7 & 7.2 & 53.6 & 63.67 & & 6.0 & 51.1 & 3.20 \\
\hline 78 & 6 & 3.1 & .00 & .5 & 7.8 & & & 20.7 & .9 & 6 & & 48 & & 0 & 3 & 60.8 & & 8 & .40 \\
\hline 79 & 8.7 & 3.8 & 10 & 3 & 1 & & 1 & .2 & .9 & 5 & 49.7 & 49.4 & & 5 & 69.00 & & & 6 & 40 \\
\hline 180 & .7 & 54.1 & 34.90 & 34.9 & 78.6 & & 69.4 & 18.3 & .0 & 1 & 49.6 & 50.8 & & .3 & 0 & & & 1.7 & .30 \\
\hline 81 & & 3.4 & .30 & 5.1 & .9 & 7.4 & 3 & 7.8 & .8 & 56.6 & 48.0 & 52.2 & & 9 & & & & .5 & .00 \\
\hline 982 & 8 & 52.1 & 35.80 & 35.0 & 80.2 & 8. & 68.4 & 17.0 & 3.4 & 56.1 & 46.7 & 52.5 & 32.8 & .1 & 0 & & & 48.7 & .25 \\
\hline 83 & .6 & 51.9 & 6.60 & 5.0 & .8 & & 68.8 & 16.0 & 38.6 & 57.2 & 45.5 & 53.0 & 31. & 58.1 & 64.50 & & & 48.0 & 9.50 \\
\hline 84 & .1 & 52.0 & .70 & 1.9 & .3 & & 69.0 & 14.9 & .0 & 57.0 & 45.3 & 53. & 30. & 58.3 & 59. & & & 47.5 & 8.20 \\
\hline 1985 & .6 & 52.4 & 32.60 & 34.7 & 78.2 & 8. & 69.1 & 13.6 & 37.5 & 54.2 & 42.5 & 52.3 & 28.7 & 57.5 & 56.00 & 54.6 & 3 & 46.2 & 17.40 \\
\hline 86 & 6 & .5 & .00 & .9 & .4 & & 0 & 12 & .2 & & 40.4 & 51.1 & & & & & & 8 & 7.00 \\
\hline 87 & 6 & 51.6 & 32.90 & 3.3 & 75.0 & & 70.7 & 11. & 36.3 & 50.2 & 40.0 & 49.8 & 24.9 & 7 & & & & 44.5 & 6.50 \\
\hline 88 & 9 & 1.4 & .30 & 3.1 & .8 & & .3 & 1.2 & 4.9 & 50.5 & 39.8 & 48.1 & 1.7 & .1 & 0 & 3 & 4 & 42.6 & 6.20 \\
\hline 89 & & 2.4 & .00 & & 6 & & & & & & & 46.1 & & & & & & 40.6 & 5.90 \\
\hline 90 & 9 & 53.9 & 32.90 & 1.2 & .3 & & 72.3 & 10.1 & 32.4 & 51.1 & 38.8 & 44.7 & 25.5 & 8.5 & 0 & 7 & 0 & 39.3 & 15.50 \\
\hline 91 & & t.5 & .30 & .0 & & & & 10.0 & 32.4 & & & 42 & & & & & & 38.5 & 5.50 \\
\hline & 44.3 & 54.3 & 10 & 9 & 75.8 & & 76 & 10 & 32. & 51 & 38 & 41. & & & & & & 37.2 & 5.10 \\
\hline 1993 & 43.2 & 55.0 & 32.80 & 31.8 & .3 & & 78.8 & 10.1 & 31.1 & 50.0 & 39.2 & 40.7 & 25.9 & .0 & 60 & 6 & 9 & 36.1 & 5.10 \\
\hline 1994 & & 54.7 & 20 & 4 & & & 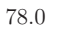 & 10. & 50. & & & 39.0 & & & & & & 34.2 & 4.90 \\
\hline 95 & 1.1 & 55.7 & 80 & 9.2 & .0 & & 792 & 9 & 29.6 & 1 & 38 & 38.6 & 25.7 & 3 & U & & & 1.1 & 1.30 \\
\hline 96 & .1 & 55.9 & 34.00 & 27.8 & & & 78.8 & 9. & 0. & 45.4 & 37.4 & 38.4 & 25.1 & 56.3 & 24.90 & 24.8 & 82.7 & 33.2 & 14.00 \\
\hline 1997 & 38.9 & 56.0 & 28.80 & 27.0 & 75.6 & & 79.4 & 9.8 & 28.6 & 44.4 & 36.2 & 38.0 & 25. & 55.5 & 23.60 & 24.3 & & 32.1 & 13.60 \\
\hline 1998 & & 00.4 & 5.00 & 20.9 & & & 17.8 & 9.8 & & 42.4 & & & & & & & & 31.5 & 13.40 \\
\hline 1999 & 7.4 & 55.1 & 27.90 & 25.6 & 76.3 & 14.5 & 77.4 & 9.8 & 26.1 & 40.6 & 36.1 & 35.7 & 24.6 & 54.8 & 21.90 & 23.5 & 80.6 & 31.4 & 13.40 \\
\hline
\end{tabular}


Table A5: Indices for bargaining coverage

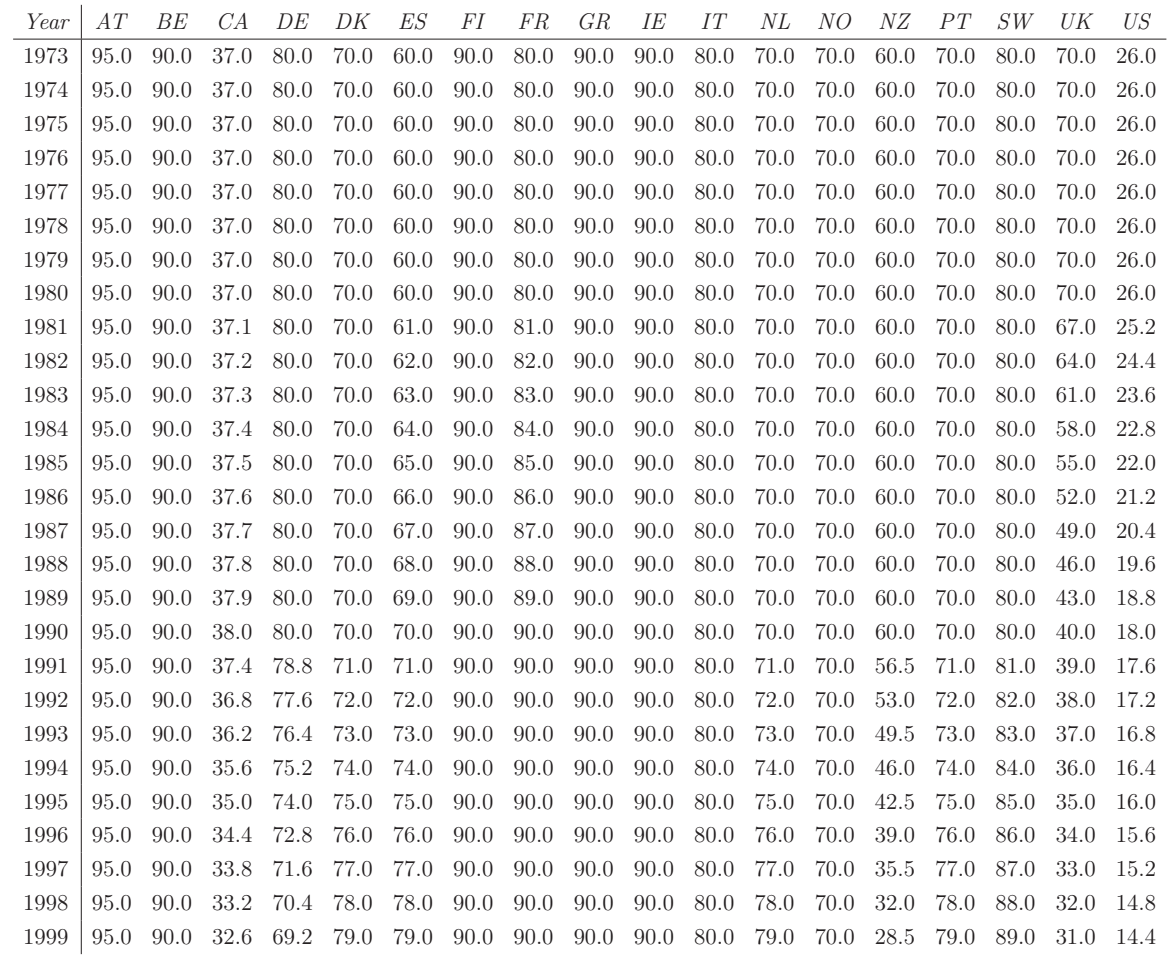

Table A6: Indices of centralisation

\begin{tabular}{|c|c|c|c|c|c|c|c|c|c|c|c|c|c|c|c|c|c|}
\hline Year & $A T$ & $B E$ & $C A$ & $D E$ & $D K$ & $E S$ & $F I$ & $F R$ & $I E$ & $I T$ & $N L$ & NO & $N Z$ & $P T$ & $S W$ & UK & $U S$ \\
\hline 973 & 3.0 & 4.0 & 1.0 & 3.0 & 5.0 & 5.0 & 5.0 & 2.0 & 4.0 & 2.0 & 3.0 & 4.5 & 3.0 & 5.0 & 5.0 & 2.0 & 1.0 \\
\hline 974 & 3.0 & 4.0 & 1.0 & 3.0 & 5.0 & 5.0 & 5.0 & 2.0 & 4.0 & 2.0 & 3.0 & 4.5 & 3.0 & 5.0 & 5.0 & 2.0 & 1.0 \\
\hline 1975 & 3.0 & 3.5 & 1.0 & 3.0 & 5.0 & 4.0 & 5.0 & 2.0 & 4.0 & 2.0 & 3.0 & 4.5 & 3.0 & 4.0 & 5.0 & 2.0 & 1.0 \\
\hline 1976 & 3.0 & 3.5 & 1.0 & 3.0 & 5.0 & 4.0 & 5.0 & 2.0 & 4.0 & 2.0 & 3.0 & 4.5 & 3.0 & 4.0 & 5.0 & 2.0 & 1.0 \\
\hline 1977 & 3.0 & 3.5 & 1.0 & 3.0 & 5.0 & 4.0 & 5.0 & 2.0 & 4.0 & 2.0 & 3.0 & 4.5 & 3.0 & 4.0 & 5.0 & 2.0 & 1.0 \\
\hline 1978 & 3.0 & 3.5 & 1.0 & 3.0 & 5.0 & 4.0 & 5.0 & 2.0 & 4.0 & 2.0 & 3.0 & 4.5 & 3.0 & 4.0 & 5.0 & 2.0 & 1.0 \\
\hline 979 & 3.0 & 3.5 & 1.0 & 3.0 & 5.0 & 4.0 & 5.0 & 2.0 & 4.0 & 2.0 & 3.0 & 4.5 & 3.0 & 4.0 & 5.0 & 2.0 & 1.0 \\
\hline 1980 & 3.0 & 3.0 & 1.0 & 3.0 & 3.0 & 4.0 & 4.0 & 2.0 & 1.0 & 3.5 & 3.0 & 3.5 & 3.0 & 3.0 & 4.5 & 1.0 & 1.0 \\
\hline 981 & 3.0 & 3.0 & 1.0 & 3.0 & 3.0 & 4.0 & 4.0 & 2.0 & 1.0 & 3.5 & 3.0 & 3.5 & 3.0 & 3.0 & 4.5 & 1.0 & 1.0 \\
\hline 982 & 3.0 & 3.0 & 1.0 & 3.0 & 3.0 & 4.0 & 4.0 & 2.0 & 1.0 & 3.5 & 3.0 & 3.5 & 3.0 & 0 & 4.5 & 1.0 & 1.0 \\
\hline 1983 & 3.0 & 3.0 & 1.0 & 3.0 & 3.0 & 4.0 & 4.0 & 2.0 & 1.0 & 3.5 & 3.0 & 3.5 & 3.0 & 3.0 & 4.5 & 1.0 & 1.0 \\
\hline 1984 & 3.0 & 3.0 & 1.0 & 3.0 & 3.0 & 4.0 & 4.0 & 2.0 & 1.0 & 3.5 & 3.0 & 3.5 & 3.0 & 3.0 & 4.5 & 1.0 & 1.0 \\
\hline 1985 & 3.0 & 3.0 & 1.0 & 3.0 & 3.0 & 3.5 & 5.0 & 2.0 & 2.5 & 2.0 & 3.0 & 4.5 & 3.0 & 3.0 & 3.0 & 1.0 & 1.0 \\
\hline 1986 & 3.0 & 3.0 & 1.0 & 3.0 & 3.0 & 3.5 & 5.0 & 2.0 & 2.5 & 2.0 & 3.0 & 4.5 & 3.0 & 3.0 & 3.0 & 1.0 & 1.0 \\
\hline 1987 & 3.0 & 3.0 & 1.0 & 3.0 & 3.0 & 3.5 & 5.0 & 2.0 & 2.5 & 2.0 & 3.0 & 4.5 & 3.0 & 3 & 3.0 & 1.0 & 1.0 \\
\hline 1988 & 3.0 & 3.0 & 1.0 & 3.0 & 3.0 & 3.5 & 5.0 & 2.0 & 2.5 & 2.0 & 3.0 & 4.5 & 3.0 & 3.0 & 3.0 & 1.0 & 1.0 \\
\hline 1989 & 3.0 & 3.0 & 1.0 & 3.0 & 3.0 & 3.5 & 5.0 & 2.0 & 2.5 & 2.0 & 3.0 & 4.5 & 3.0 & 3.0 & 3.0 & 1.0 & 1.0 \\
\hline 1990 & 3.0 & 3.0 & 1.0 & 3.0 & 3.0 & 3.0 & 5.0 & 2.0 & 4.0 & 2.0 & 3.0 & 4.5 & 1.0 & 4.0 & 3.0 & 1.0 & 1.0 \\
\hline 1991 & 3.0 & 3.0 & 1.0 & 3.0 & 3.0 & 3.0 & 5.0 & 2.0 & 4.0 & 2.0 & 3.0 & 4.5 & 1.0 & 4.0 & 3.0 & 1.0 & 1.0 \\
\hline 1992 & 3.0 & 3.0 & 1.0 & 3.0 & 3.0 & 3.0 & 5.0 & 2.0 & 4.0 & 2.0 & 3.0 & 4.5 & 1.0 & 4. & 3.0 & 1.0 & 1.0 \\
\hline 1993 & 3.0 & 3.0 & 1.0 & 3.0 & 3.0 & 3.0 & 5.0 & 2.0 & 4.0 & 2.0 & 3.0 & 4.5 & 1.0 & 4.0 & 3.0 & 1.0 & 1.0 \\
\hline 1994 & 3.0 & 3.0 & 1.0 & 3.0 & 3.0 & 3.0 & 5.0 & 2.0 & 4.0 & 2.0 & 3.0 & 4.5 & 1.0 & 4.0 & 3.0 & 1.0 & 1.0 \\
\hline 1995 & 3.0 & 3.0 & 1.0 & 3.0 & 2.0 & 3.0 & 5.0 & 2.0 & 4.0 & 2.0 & 3.0 & 4.5 & 1.0 & 4.0 & 3.0 & 1.0 & 1.0 \\
\hline 1996 & 3.0 & 3.0 & 1.0 & 3.0 & 2.0 & 3.0 & 5.0 & 2.0 & 4.0 & 2.0 & 3.0 & 4.5 & 1.0 & 4.0 & 3.0 & 1.0 & 1.0 \\
\hline 1997 & 3.0 & 3.0 & 1.0 & 3.0 & 2.0 & 3.0 & 5.0 & 2.0 & 4.0 & 2.0 & 3.0 & 4.5 & 1.0 & 4.0 & 3.0 & 1.0 & 1.0 \\
\hline 1998 & 3.0 & 3.0 & 1.0 & 3.0 & 2.0 & 3.0 & 5.0 & 2.0 & 4.0 & 2.0 & 3.0 & 4.5 & 1.0 & 4.0 & 3.0 & 1.0 & 1.0 \\
\hline 1999 & 3.0 & 3.0 & 1.0 & 3.0 & 2.0 & 3.0 & 5.0 & 2.0 & 4.0 & 2.0 & 3.0 & 4.5 & 1.0 & 4.0 & 3.0 & 1.0 & 1.0 \\
\hline
\end{tabular}




\section{B Results with country specific and period specific underlying distributions and country-year specific symmetric distribu- tion}

Table B1: Results with country specific and period specific underlying distributions and country-year specific symmetric distribution. The period specific underlying distributions are based on observations from the periods 1973-79, 1980-89, 1990-94 and 1995-1999 respectively.

\begin{tabular}{|c|c|c|c|c|c|c|c|c|c|c|}
\hline \multirow[b]{2}{*}{ Category } & \multirow[b]{2}{*}{$Y$} & \multicolumn{3}{|c|}{ Country specific shape } & \multicolumn{3}{|c|}{ Period specific shape } & \multicolumn{3}{|c|}{ Symmetric } \\
\hline & & $\overline{F W C P}$ & $\hat{q}-q$ & $p$ & $F W C P$ & $\hat{q}-q$ & $p$ & $F W C P$ & $\hat{q}-q$ & $p$ \\
\hline All & 324 & 0.181 & 0.008 & 000 & 0.196 & 0.008 & 0.000 & 0.200 & 0.009 & 0.000 \\
\hline 1970-79 & 5 & 0.602 & 0.003 & 013 & 0.603 & 0.003 & 0.015 & 0.501 & 0.002 & 0.061 \\
\hline 1980-89 & 74 & 0.304 & 0.009 & 000 & 0.292 & 0.008 & 0.000 & 0.230 & 0.006 & 0.009 \\
\hline 1990-94 & 93 & 0.157 & 0.009 & .029 & 0.190 & 0.011 & 0.009 & 0.213 & 0.013 & 0.005 \\
\hline 1995-99 & 152 & 0.087 & 0.009 & 0.098 & 0.112 & 0.011 & 0.044 & 0.159 & 0.017 & 0.005 \\
\hline Anglo & 153 & 0.110 & 0.006 & 0.054 & 0.132 & 0.008 & 0.026 & 0.124 & 0.007 & 0.029 \\
\hline Core & 125 & 0.158 & 0.008 & 13 & 0.172 & 0.008 & 0.006 & 0.220 & 0.011 & 0.000 \\
\hline Nordic & 18 & 0.330 & 0.004 & 0.033 & 0.458 & 0.008 & 0.001 & 0.359 & 0.005 & 0.018 \\
\hline South & 28 & 0.424 & 0.014 & 0.001 & 0.344 & 0.010 & 0.007 & 0.333 & 0.010 & 0.007 \\
\hline Austria & 2 & 0.380 & 0.003 & 0.373 & 0.681 & 0.010 & 0.045 & 0.019 & 0.000 & 0.661 \\
\hline Belgium & 31 & 0.102 & 0.006 & 0.252 & 0.189 & 0.013 & 0.079 & 0.205 & 0.014 & 0.038 \\
\hline Canada & 57 & 0.014 & 0.001 & 481 & 0.013 & 0.001 & 0.492 & 0.047 & 0.004 & 0.366 \\
\hline Denmark & 8 & 0.197 & 0.004 & 0.335 & 0.373 & 0.010 & 0.106 & 0.336 & 0.009 & 0.138 \\
\hline Finland & 2 & -0.070 & -0.000 & 0.715 & 0.631 & 0.009 & 0.090 & 0.601 & 0.008 & 0.108 \\
\hline France & 21 & -0.067 & -0.002 & 0.680 & -0.242 & -0.007 & 0.905 & -0.050 & -0.002 & 0.663 \\
\hline Germany & 16 & 0.108 & 0.003 & 0.365 & -0.028 & -0.001 & 0.613 & 0.060 & 0.002 & 0.460 \\
\hline Greece & 7 & 0.271 & 0.006 & 0.250 & -0.137 & -0.002 & 0.722 & -0.000 & -0.000 & 0.605 \\
\hline Ireland & 27 & 0.193 & 0.014 & 0.134 & 0.252 & 0.020 & 0.059 & 0.035 & 0.002 & 0.471 \\
\hline Italy & 0 & 1.000 & 0.009 & & 1.000 & 0.009 & 0.047 & - & 0.000 & 1.000 \\
\hline Luxembourg & 32 & 0.138 & 0.012 & 0.191 & 0.185 & 0.017 & 0.102 & 0.275 & 0.029 & 0.018 \\
\hline Netherlands & 23 & 0.357 & 0.026 & 0.004 & 0.337 & 0.024 & 0.007 & 0.395 & 0.031 & 0.001 \\
\hline New Zealand & 45 & 0.125 & 0.009 & 0.176 & 0.145 & 0.010 & 0.141 & 0.238 & 0.019 & 0.022 \\
\hline Norway & 2 & 0.593 & 0.004 & 0.131 & 0.489 & 0.003 & 0.252 & - & 0.000 & 1.000 \\
\hline Portugal & 3 & 0.804 & 0.030 & 0.000 & 0.840 & 0.038 & 0.000 & 0.823 & 0.034 & 0.000 \\
\hline Spain & 18 & 0.129 & 0.010 & 0.319 & -0.212 & -0.012 & 0.839 & 0.001 & 0.000 & 0.567 \\
\hline Sweden & 6 & 0.401 & 0.009 & 0.087 & 0.461 & 0.011 & 0.043 & 0.454 & 0.011 & 0.051 \\
\hline UK & 18 & 0.204 & 0.007 & 0.151 & 0.180 & 0.006 & 0.193 & 0.217 & 0.008 & 0.129 \\
\hline US & 6 & 0.119 & 0.002 & 0.472 & 0.227 & 0.003 & 0.339 & -0.206 & -0.002 & 0.770 \\
\hline
\end{tabular}

Notes: Under the symmetry approach, we do not simulate any notional wage cuts for Italy and Norway, hence the FWCP is not defined for these countries. See also notes to Table 1 


\section{European Central Bank Working Paper Series}

For a complete list of Working Papers published by the ECB, please visit the ECB's website (http://www.ecb.int)

745 "Market discipline, financial integration and fiscal rules: what drives spreads in the euro area government bond market?" by S. Manganelli and G.Wolswijk,April 2007.

746 "U.S. evolving macroeconomic dynamics: a structural investigation" by L. Benati and H. Mumtaz,April 2007.

747 "Tax reform and labour-market performance in the euro area: a simulation-based analysis using the New Area-Wide Model" by G. Coenen, P. McAdam and R. Straub, April 2007.

748 "Financial dollarization: the role of banks and interest rates" by H. S. Basso, O. Calvo-Gonzalez and M. Jurgilas, May 2007.

749 "Excess money growth and inflation dynamics" by B. Roffia and A. Zaghini, May 2007.

750 "Long run macroeconomic relations in the global economy" by S. Dees, S. Holly, M. H. Pesaran and L.V. Smith, May 2007.

751 "A look into the factor model black box: publication lags and the role of hard and soft data in forecasting GDP” by M. Bańbura and G. Rünstler, May 2007.

752 "Econometric analyses with backdated data: unified Germany and the euro area" by E.Angelini and M. Marcellino, May 2007.

753 “Trade credit defaults and liquidity provision by firms" by F. Boissay and R. Gropp, May 2007.

754 "Euro area inflation persistence in an estimated nonlinear DSGE model" by G.Amisano and O.Tristani, May 2007.

755 "Durable goods and their effect on household saving ratios in the euro area" by J.Jalava and I. K. Kavonius, May 2007.

756 "Maintaining low inflation: money, interest rates, and policy stance" by S. Reynard, May 2007.

757 "The cyclicality of consumption, wages and employment of the public sector in the euro area" by A. Lamo, J.J. Pérez and L. Schuknecht, May 2007.

758 "Red tape and delayed entry" by A. Ciccone and E. Papaioannou, June 2007.

759 "Linear-quadratic approximation, external habit and targeting rules" by P. Levine, J. Pearlman and R. Pierse, June 2007.

760 "Modelling intra- and extra-area trade substitution and exchange rate pass-through in the euro area" by A. Dieppe and T.Warmedinger, June 2007.

761 "External imbalances and the US current account: how supply-side changes affect an exchange rate adjustment" by P. Engler, M. Fidora and C. Thimann, June 2007.

762 "Patterns of current account adjustment: insights from past experience" by B. Algieri and T. Bracke, June 2007.

763 "Short- and long-run tax elasticities: the case of the Netherlands" by G.Wolswijk, June 2007. 
764 "Robust monetary policy with imperfect knowledge" by A. Orphanides and J. C. Williams, June 2007.

765 "Sequential optimization, front-loaded information, and U.S. consumption" by A.Willman, June 2007.

766 "How and when do markets tip? Lessons from the Battle of the Bund" by E. Cantillon and P.-L.Yin, June 2007.

767 "Explaining monetary policy in press conferences" by M. Ehrmann and M. Fratzscher, June 2007.

768 "A new approach to measuring competition in the loan markets of the euro area" by M. van Leuvensteijn, J.A. Bikker,A. van Rixtel and C. Kok Sørensen, June 2007.

769 “The 'Great Moderation' in the United Kingdom” by L. Benati, June 2007.

770 "Welfare implications of Calvo vs. Rotemberg pricing assumptions" by G. Lombardo and D.Vestin, June 2007.

77I "Policy rate decisions and unbiased parameter estimation in typical monetary policy rules" by J. Podpiera, June 2007.

772 "Can adjustment costs explain the variability and counter-cyclicality of the labour share at the firm and aggregate level?” by P. Vermeulen, June 2007.

773 "Exchange rate volatility and growth in small open economies at the EMU periphery" by G. Schnabl, July 2007.

774 "Shocks, structures or monetary policies? The euro area and US after 200I" by L. Christiano, R. Motto and M. Rostagno, July 2007.

775 "The dynamic behaviour of budget components and output" by A. Afonso and P. Claeys, July 2007.

776 “Insights gained from conversations with labor market decision makers” by T. F. Bewley, July 2007.

777 "Downward nominal wage rigidity in the OECD" by S. Holden and F.Wulfsberg, July 2007. 


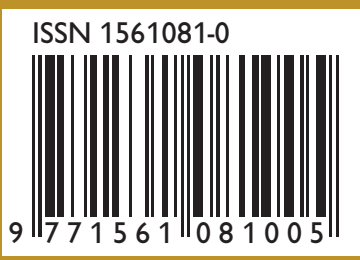

